\title{
CHAPTER 8 \\ Polymeric Nanoparticles and Cancer: Lessons Learnt from CRLX101
}

\author{
ISMAEL GRITLI, ${ }^{\mathrm{a}}$ EDWARD GARMEY, ${ }^{\mathrm{b}}$ SCOTT ELIASOF,${ }^{\mathrm{b}}$ \\ ANDRES TELLEZ, ${ }^{\mathrm{b}}$ MARK E. DAVIS ${ }^{\mathrm{c}}$ AND YEN YUN ${ }^{* \mathrm{~d}}$
}

\author{
${ }^{a}$ College of Medical Science and Technology, Taipei Medical University, \\ 250-Wu-xing St. Xinyi District, Taipei 11031, Taiwan; ${ }^{\mathrm{b}}$ Cerulean Pharma \\ Inc., 840 Memorial Drive, Cambridge, MA 02139, USA; ${ }^{\mathrm{c}}$ Chemical \\ Engineering, California Institute of Technology, Pasadena, CA 91125, USA; \\ ${ }^{\mathrm{d}}$ City of Hope National Medical Center, 1500 Duarte Rd, Duarte, \\ CA 91010, USA \\ *Email: YYen@coh.org
}

\subsection{Introduction}

CRLX101 (formerly IT-101) is a novel cyclodextrin-based polymer that selfassembles into nanoparticles. CRLX101 was designed to deliver sustained levels of the cytotoxic agent camptothecin (CPT) to tumour cells while minimizing delivery to normal tissue. Covalent conjugation of hydrophobic CPT to the cyclodextrin polymer increases its water solubility by three orders of magnitude and prevents inactivation through spontaneous lactone ring opening, a process that occurs rapidly at physiologic $\mathrm{pH}^{1}$

CPT derivatives such as irinotecan (CPT-11, Camptosar ${ }^{\circledR} ;$ Pfizer) and topotecan (TPT, Hycamtin ${ }^{\circledR}$; GlaxoSmithKline) demonstrate clinical utility for the treatment of advanced solid tumours. The primary cellular target of

RSC Drug Discovery Series No. 51

Nanomedicines: Design, Delivery and Detection

Edited by Martin Braddock

(C) The Royal Society of Chemistry 2016

Published by the Royal Society of Chemistry, www.rsc.org 
CPT is the topoisomerase-1 (TOP1)-DNA cleavage complex which, when stabilised, prevents TOP1-mediated unwinding and subsequent DNA repair. Exposure of cancer cells to CPT leads to replication-mediated accumulation of double-stranded DNA breaks and apoptosis. However, the interaction of CPT with DNA is non-covalent and reverses within minutes of drug removal. ${ }^{2}$ More recently, CPT and prolonged low-dose TPT have been shown to downregulate hypoxia-inducible factor 1 (HIF-1 $\alpha$ ), which is associated with angiogenesis, metastasis, and resistance to vascular endothelial growth factor (VEGF) inhibition. Both mechanisms of action have important pharmacological implications that favour sustained exposure of tumours to active concentrations of these compounds. ${ }^{3}$ However, CPT derivatives are associated with considerable toxicity, including diarrhoea and myelosuppression. ${ }^{4,5}$

In preclinical studies, CRLX101 nanoparticles demonstrated reduced rapid renal clearance compared to $\mathrm{CPT}$, resulting in a prolonged plasma half-life compared to small-molecule CPT analogues. Furthermore, in tumour xenograft models, CRLX101 accumulated preferentially in tumour tissue because of the enhanced permeability of tumour neo-vasculature (Figure 8.1). Notably, prolonged release of active CPT from CRLX101 nanoparticles has been observed in tumour tissue resulting in enhanced TOP1 inhibition, potential HIF-1 $\alpha$ effect, and increased antitumour activity against multiple human tumour xenografts (e.g. lymphoma, breast cancer, ovarian cancer, lung cancer, and colon cancer) compared to CPT-11 and TPT. ${ }^{6,7}$

In the first-in-human phase I clinical trial of CRLX101 that was designed to determine the toxicity, safety profile, and pharmacokinetics of CRLX101, the maximally tolerated dose (MTD) was determined and recommended to test in phase II studies with a weekly or bi-weekly dosing schedule. ${ }^{8}$

In this chapter, we try to position CRLX101 among relevant CPT polymeric nanoparticles and compare their mechanisms of action, chemical and physical properties and physiological outcomes. Thus, the first three sections cover a wide range of nanotherapeutic strategies to target TOP1, HIF- $1 \alpha$, and cancer stem cells. In the fourth section, we highlight the value of combining antiangiogenics with HIF-1 $\alpha$ inhibitors. Finally, we cover in detail the preclinical and clinical evaluations of CRLX101 and discuss future directions.

\subsection{Topoisomerase 1 Inhibitors}

CPT was first semi-synthesised from the Chinese tree, Camptotheca acuminata in $1966 .{ }^{9}$ CPT is a potent alkaloid cytotoxic agent that inhibits TOP1 enzymatic activity, blocks cell cycle during the S-phase and induces cellular apoptotic death. Under physiological conditions, TOP1 cuts one DNA strand, allowing the DNA to uncoil, and then re-ligates the DNA back into its supercoiled form. However, when CPT is present, it binds to the TOP1-DNA complex and prevents the re-ligation of the DNA, which eventually leads to apoptosis. CPT has low aqueous solubility in the lactone form and can be highly toxic in its carboxylate form. ${ }^{10}$ In 1972 , a phase II clinical study from 


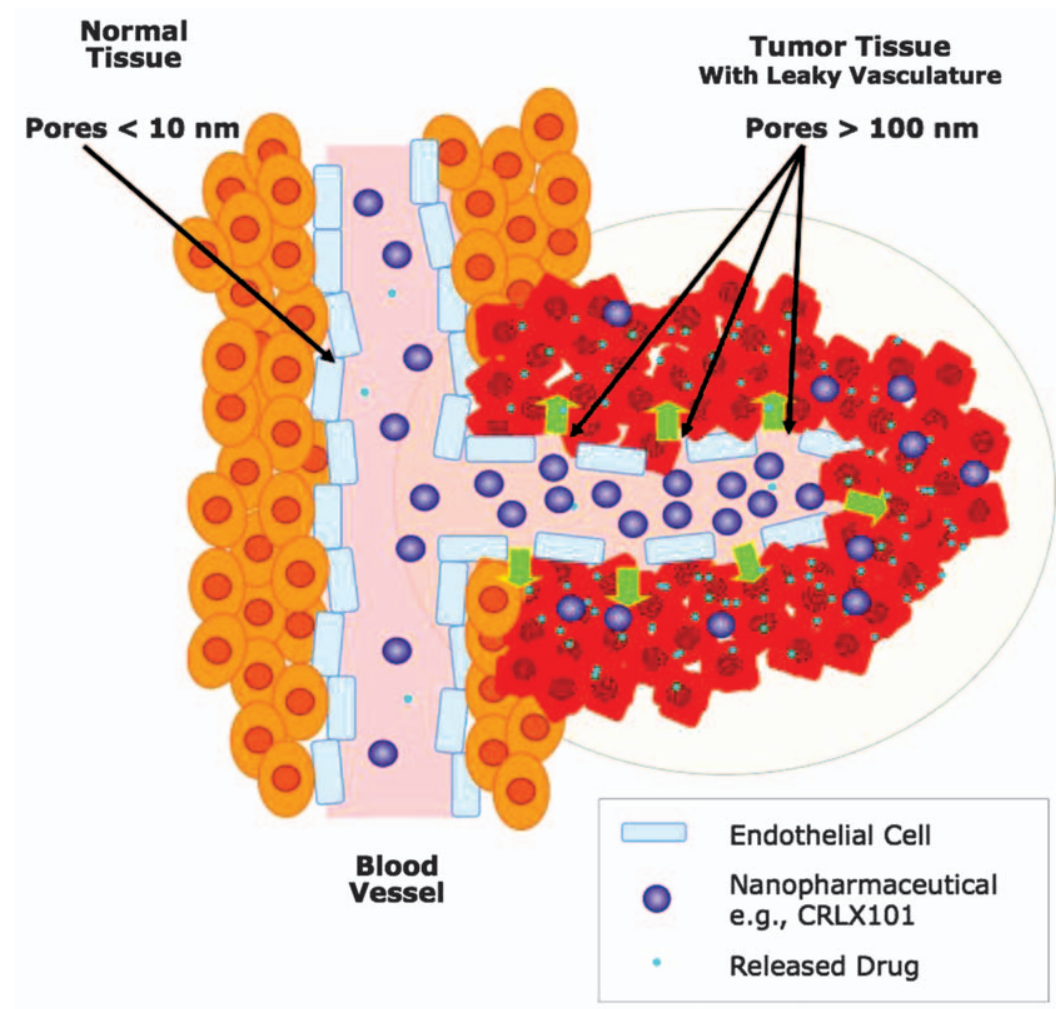

Figure 8.1 CRLX101-mediated dynamic tumour targeting. CRLX101 nanoparticles target tumours via leaky vasculature and releases their camptothecin (CPT) payload within tumour cells. This results in profound pharmacokinetic improvement, a sustained drug exposure and low systemic distribution.

the Mayo Clinic evaluated the sodium carboxylate form of CPT in 61 patients, and objective responses after 2 months were observed in only two (3\%) patients with advanced gastrointestinal cancer. CPT was administered intravenously at a dose range of $90-180 \mathrm{mg} \mathrm{m}^{-2}$ every 21 days. The doselimiting toxicity was reversible bone marrow suppression (leukopaenia and thrombocytopaenia). Other toxic effects included nausea, vomiting, diarrhoea, stomatitis, dermatitis, alopecia, and haemorrhagic cystitis. Based on the high degree of toxicity and the low response rate, further clinical evaluation of CPT was discontinued. ${ }^{11}$

Hertzberg et al. ${ }^{12}$ synthesized several CPT derivatives in which the hydroxy lactone ring was modified and evaluated for inhibition of TOP1 and cytotoxicity to mammalian cells. The hydroxy lactone ring of CPT was critical for in vivo antitumour activity, consistent with earlier results, and correlated with the structure-activity relationships of TOP1 inhibition. Thus, in retrospect, it is not surprising that all prior clinical trials of CPT, in which the soluble, open ring sodium carboxylate form of CPT (i.e. lacking the hydroxy 
lactone ring) was administered, resulted in poor clinical outcome. ${ }^{12} \mathrm{~A}$ biochemical study demonstrated in 1994 that human serum albumin preferentially binds the carboxylate of CPT with a 150-fold higher affinity than the lactone form. As a result of this interaction, the lactone ring opens rapidly and fully to the carboxylate form in human plasma under physiological conditions. Because earlier studies have shown that the carboxylate form of CPT is clinically inactive, even dosing the active form of CPT (which was not done in the earlier clinical trials) would not have resulted in clinical activity, because CPT would have been rapidly converted to the inactive form upon dosing. Thus, lactone ring stabilization is required to obtain meaningful clinical activity. ${ }^{13}$

Several studies attempted to modify CPT chemical structure in order to lower its toxicity profile and increase its water solubility. Most notably, CPT-11 and TPT are two examples of CPT chemically modified to keep lactone stability and increase water solubility. CPT-11 is a prodrug that is enzymatically converted into active 7-ethyl-10-hydroxy-CPT (SN38), which is 100-1000 times more potent but less water soluble. In Japan, the use of CPT-11 was approved for small cell lung cancer (SCLC) and non-small cell lung cancer (NSCLC), cervical cancer, and ovarian cancer. In Europe, the use CPT-11 was approved for second-line monotherapy and combination with fluoropyrimidines in patients with colon cancer. In the USA, TPT was approved for use in patients with second-line ovarian cancer and SCLC. ${ }^{14}$ Water-soluble 7-modified CPT, gimatecan (ST1481) is another example that has been tested in a panel of different tumour types including platinumresistant cancer cells. Compared to TPT, gimatecan showed superior antiproliferative activity against many cancer types, except for glioma. ${ }^{15}$ In 2008 , Franco Zunino and his group at the IRCCS Foundation National Cancer Institute in Milan, Italy synthesised a novel hydrophilic CPT analogue with anti-tumour features, ST1968. To increase CPT solubility, ST1968 was synthesised by oxyiminomethylation on position 7 of CPT. Although ST1968 is less potent than other CPT derivatives such as active SN38, it showed remarkable activity against CPT-11-resistant tumour models and yeast cells transfected with mutant TOP1. ${ }^{16}$ In 2008, another study from the same group identified a novel TOP1 inhibitor, topopyrone $\mathrm{C}$, isolated from the fungi Phoma and Penicillium and successfully synthesized and modified it in vitro. ${ }^{17,18}$ Cananzi et al. described in 2011 a novel analogue of lamellarin D that inhibited TOP1 and exhibited anti-tumour activity against NSCLC cells. ${ }^{19}$ Recently, Cincinelli et al. synthesized a novel hybrid CPT-platinum anticancer agent. 7-oxyiminomethyl CPT was linked to diaminedichloroplatinum and tested for activity against a panel of cancer cells including TPT- and platinum-resistant types. In vivo studies on H460 human NSCLC xenografts showed $82 \%$ tumour volume inhibition. This hybrid agent was well tolerated at higher doses than those established for cisplatin but at lower doses than those established for CPT- $11 .^{20}$

Novel strategies to modify CPT water solubility and lower its toxicity also include the use of polymeric nanoparticles. In order to achieve a successful 
nanotherapeutic approach, three criteria have been suggested. (1) Nanoparticles must evade immunorecognition. For example, some approaches use polyethylene glycol (PEG) to mask nanoparticles from the immune system. (2) Nanoparticles must be eliminated after the biological effect has occurred. For instance, biodegradable materials can be used to control cellular uptake and the release rate of the free drug. (3) Nanoparticles must be delivered and accumulated preferentially in target tissue. ${ }^{21}$ Besides active targeting that involves certain molecules with specific affinity to tumours, high molecular weight nanoparticles can passively accumulates in tumour tissue due to an enhanced permeation and retention (EPR) effect, and this accumulation can be sustained for a substantial amount of time since tumour tissues severely lack functional lymphatic vasculature. ${ }^{22}$

\subsubsection{Carbohydrate-based Polymeric Nanoparticles}

Mersana Therapeutics developed a carbohydrate-derived polymeric nanoparticle called XMT-1001, which uses a 40-70 kDa biodegradable hydrophilic polyacetal, poly(1-hydroxymethylethylene hydroxymethylformal) "Fleximer" conjugate to increase the solubility of CPT. XMT-1001 loaded with $7.5 \mathrm{wt} \%$ CPT showed improved antineoplastic efficacy against LS174T human colon tumour and A2780 human ovarian tumour xenografts in mice. Although accumulation in tumour tissue was detected, most carrier nanoparticles remained in circulation and free CPT levels were substantially high in liver tissue. ${ }^{23}$ In a dose-escalation phase I study of 49 patients with advanced solid tumours (ClinicalTrials.gov identifier NCT00455052), intravenous administration of XMT-1001 at a dose range of $1-85 \mathrm{mg} \mathrm{m}^{-2}$ of CPT equivalent showed favourable pharmacokinetics with sustained free CPT plasma levels beyond 24 hours post-administration. Although no haemorrhagic cystitis or diarrhoea was detected, the highest dose caused grade 3 and grade 4 neutropaenia in two patients. 12 patients with refractory tumours had stable disease for more than 12 weeks, most of whom had pancreatic or NSCLC. ${ }^{24}$

Ochi and colleagues at Daiichi Sankyo Company (Japan) described a novel CPT-analogue nanoparticle DE-310 with potent antitumour activity. DE-310 is a carboxymethyldextran polyalcohol (CM-Dex-PA) - a class of polyhydroxylated carboxymethylpolysaccharides, which is linked to a hexacyclic CPT-derivative compound called DX-8951 monomethanesulfonate dehydrate (DX-8951f, also known as exatecan). In the nanoparticle, exatecan payload was linked via a Gly-Gly-Phe-Gly tetrapeptide spacer and achieved a loading capacity of 5-7 wt\%. The DE-310 nanoparticle has a relatively large molecular size $(360 \mathrm{kDa})$ and thus could passively target tumour tissue through the EPR effect and efficiently delay renal filtration. In a murine malignant fibrosarcoma ascites model, DE-310 showed prolonged survival up to $300 \%$ and free DX-8951 could be detected in both serum and ascites fluid. DE-310 seemed to be preferentially taken up by tumour cells than macrophages nearby. One possible explanation for this is the nanoparticle's high hydrophilicity, which could have caused decreased endocytic response 
of macrophages. The rationale for using the Gly-Gly-Phe-Gly spacer in DE-310 was to provide a sustained release of DX-8951 at a slow rate into the tumour tissue without prematurely releasing the drug into the peripheral circulation. Gly-Gly-Phe-Gly tetrapeptide is predominantly cleaved by cysteine proteases, which are reportedly overexpressed in a wide range of malignant tumours, including colon cancer (cathepsin $\mathrm{H}$ ), metastatic bone marrow tumours (cathepsin L), and many other malignant tumour types (cathepsin B). Hence, once DE-310 is endocytosed by tumour cells, proteolytic lysosomal activity releases the free drug. ${ }^{25,26}$

T-0128 (MEN4901; Tanabe Seiyaku, Japan) is a $130 \mathrm{kDa}$ polymeric nanoparticle conjugate of a novel CPT analogue (7-ethyl-10-aminopropyloxy-CPT or T-2513) to carboxymethyl dextran (CM-Dex). Unlike DE-310, this nonPA-polysaccharide nanoparticle's Gly-Gly-Gly linker allowed T-0128 to be preferentially taken up by macrophages or macrophage-like tumour cells. Tumour-associated cathepsins were shown to be responsible for the lysosomal drug release. ${ }^{27}$ In vitro studies showed that T-0128 did not accumulate in malignant tumour cells including highly refractory Walker-256 rat carcinoma and B16 melanoma cells, while macrophage-like cells, such as J774.1, internalized T-0128 very efficiently. Fluorescein isothiocyanate dextran uptake suggested that T-0128 was possibly taken up by macrophages through fluid-phase pinocytosis. ${ }^{28}$ Surprisingly, other studies showed that intravenous administration of T-0128 in several xenograft models including Walker-256 carcinoma, MX-1 mammary carcinoma, LX-1 lung carcinoma, St-4 gastric, and HT-29 colorectal tumours showed prolonged survival and tumour growth delay, many of which are highly refractory to CPT-11 and TPT. $^{29}$ Pharmacokinetic studies demonstrated that T-0128 could achieve relatively long plasma half-life and efficient tumour targeting. Nevertheless, substantial amounts of T-0128 nanoparticles were taken up by hepatic and splenic tissue and could potentially cause severe toxicities. ${ }^{30}$

\subsubsection{Polyamine Polymeric Nanoparticles}

Developed by Cell Therapeutics (Seattle, WA, USA), CT-2106 is a poly(Lglutamic acid) conjugate to $20(S)$-camptothecin (PG-CPT). The $20(S)$-hydroxyl group of CPT is linked to multiple $\gamma$-carboxylate sites on the PG polymer. Using a glycine linker, CPT loading on the polymer achieved up to $50 \mathrm{wt} \%$. The high molecular weight of the PG anionic polymer not only increased CPT solubility, but also improved tumour penetration through the EPR effect and enhanced tumour growth inhibition compared to free CPT. Another feature of PG-CPT is its biodegradability which allows for the slow release of active CPT from nanoparticles once they are endocytosed by target cells. ${ }^{31}$ Preclinically, CT-2106 showed potent antitumour activity against a drugresistant human NSCLC cell line. Intravenous injection resulted in delayed tumour growth and prolonged median overall survival (mOS) up to four-fold in a nude mouse xenograft model. Additionally, CT-2106 showed favourable pharmacokinetics and a slow CPT release rate (1\% per day) under $\mathrm{pH}$-neutral 
conditions. $^{32}$ In 2003, phase I studies of CT-2106 in patients with advanced solid tumours were conducted (ClinicalTrials.gov identifier NCT00059917). Endpoints were to determine the MTD, toxicity, pharmacokinetics, and response rate of CT-2106. Patients with melanoma were the predominant population in the study. Fewer than $20 \%$ of patients had haematologyrelated toxicities (mostly anaemia). Although the study showed favourable pharmacokinetics and slower urinary excretion, no objective response (neither partial nor complete) was observed. ${ }^{33}$ In 2006, CT-2106 entered phase II clinical trials for the second-line treatment of ovarian cancer. Primary endpoints were to measure response rate and secondary measurements were of toxicity, response duration, time to progression (TTP), and survival (ClinicalTrials.gov identifier NCT00291837).

Dallavalle et al. described in 2006 the synthesis of a series of novel CPT-conjugates with a polyamine chain linked to position 7 of CPT via an iminomethyl group. The compounds showed TOP1 inhibition and antitumour activity against $\mathrm{H} 460$ human NSCLC cells. Moreover, polyamine conjugation to CPT enhanced its solubility and tumour growth inhibitor effects. ${ }^{34}$

Dal Pozzo et al. designed novel tumour-targeted RGD (Arg-Gly-Asp) peptide-camptothecin conjugates. RGD cyclopeptides showed high affinity to $\alpha_{\mathrm{V}}$ integrin receptors, which are preferentially overexpressed in tumour cells. By conjugating RGD cyclopeptides to CPT, selective tumour tissue targeting could be anticipated, and thus toxicity reduced. In fact, RGD peptide-CPT conjugates showed high affinity to integrin $\alpha_{V}$ and internalised into tumour cells overexpressing integrin $\alpha_{V}$ [A498 renal cell carcinoma (RCC) and A2780 ovarian carcinoma], but not tumour cells with low levels of integrins (PC3 prostate carcinoma). Moreover, tumour cells slowly internalised RGD peptide-CPT resulting in improved drug accumulation compared to free CPT treatment. In an A2780 human ovarian carcinoma xenograft model, RGD peptide-CPT conjugates were injected intraperitoneally or subcutaneously, resulting in $40 \%$ tumour growth inhibition and well-tolerated toxicities at a dose of $48 \mathrm{mg} \mathrm{kg}^{-1}$. Free-drug release rate in blood circulation was $\sim 2.5 \%$ and high levels of conjugate were detected inside tumours. ${ }^{35}$

\subsubsection{HPMA Copolymeric Nanoparticles}

HPMA copolymeric nanoparticles have been used to conjugate several cytotoxic drugs including paclitaxel (PNU166945), CPT (PNU166148 or MAG-CPT) and two platinates [AP5280 and AP5346 (ProLindac)]. ${ }^{36}$ All these nanoparticles share a common $N$-(2-hydroxypropyl)methacrylamide (HPMA) copolymer core. PNU166148 was developed by Pharmacia using HPMA and methacryloyl-glycine-ONp $95: 5$ or $90: 10$, thus the acronym MAG-CPT. CPT was modified at C-20 $\alpha$-hydroxy group with glycine, which could be hydrolysed by esterase during endocytosis. In order to conjugate HPMA to CPT, a tetrapeptide (Gly-Phe-Leu-Gly) linker was attached, which provided both lactone ring stability in blood circulation and enhanced lysosome-mediated release of free CPT inside cells. Depending on its formulation, MAG-CPT had 
molecular weight of 20.9-27.8 kDa and CPT loading capacity of 5-10 wt\%. When mixed with plasma, MAG-CPT did not aggregate and its interaction with serum albumin was weaker than that of free CPT. ${ }^{37,38}$ Pharmacokinetic studies showed significant renal elimination of hydrolysed nanoparticles. The MAG-CPT linker was later modified to Gly-C6-Gly and was selected for dose-escalation phase I studies (ClinicalTrials.gov identifier NCT00004076). The study included 23 patients who received an intravenous infusion over $30 \mathrm{~min}$ every 4 weeks. The reported recommended MTD was $200 \mathrm{mg} \mathrm{m}^{-2}$, and dose-limiting toxicities included grade 4 neutropaenia and thrombocytopaenia and grade 3 diarrhoea, and severe and unpredictable cystitis was also observed in few patients. The most pronounced adverse effect was bladder toxicity (dysuria and microscopic and macroscopic haematuria) and could only be resolved by withdrawal of treatment. One treatment-associated death was also reported. Moreover, no objective clinical responses were observed. Due to the severe bladder toxicities associated with MAG-CPT, new formulations attempted to decrease the polymer molecular weight in order to enhance urinary excretion. However, this new formula also meant that free CPT levels became lower in the tumour $\left(12.2 \mathrm{ng} \mathrm{g}^{-1}\right)$ compared to the normal tissue (21.9 $\mathrm{ng} \mathrm{g}^{-1}$ ). Based on these results, clinical development of MAG-CPT was terminated. ${ }^{39,40}$

\subsubsection{PEG Polymeric Nanoparticles}

The use of PEG in drug delivery dates back to the 1970s. In theory, attaching PEG chains to the drug molecule of interest could achieve improved drug solubility, reduced dosage frequency, reduced toxicity, extended circulating life, increased drug stability, and enhanced protection from proteolytic degradation. ${ }^{41,42}$

Prothecan is a CPT-conjugated polymeric nanoparticle that was developed by Enzon Pharmaceuticals (Plantation, FL, USA) and entered phase II studies in patients with SCLC. In 1996, Greenwald et al. conceptualized the importance of increasing water solubility of CPT by conjugating it to PEG in a similar manner to that previously described for paclitaxel. Using an alanine linker, CPT could be conjugated to PEG giving a molecular weight of $40 \mathrm{kDa}$ and dramatically improved solubility $\left(2 \mathrm{mg} \mathrm{mL}^{-1}\right.$ in water compared with $0.0025 \mathrm{mg} \mathrm{mL}^{-1}$ free CPT in water). Superior efficacy against P388 murine leukaemia and HT-29 human colorectal xenograft models and favourable pharmacokinetics ultimately led to choosing prothecan for phase I clinical studies in patients with solid tumours. Single doses of as much as $7000 \mathrm{mg} \mathrm{m}^{-2}$ could be well tolerated and major toxicities were restricted to neutropaenia and leukopaenia. Five out of 14 patients (35.7\%) exhibited stable disease and one patient (7\%) had a partial response. ${ }^{43-45}$

Enzon's second generation PEGylated CPT, pegamotecan, was developed few years later. Pegamotecan used an alanitate ester to link the hydrophobic CPT to hydrophilic PEG. Preclinical investigations showed superior antitumour activity in a human colon cancer xenograft model. Green fluorescent 
protein-labelled PEG polymers were used to study biodistribution. As expected, high molecular weight PEG passively accumulated in tumour tissue through the EPR effect and induced apoptosis in cancer cells. Importantly, liver and kidney toxicities were minimal compared to free CPT. Change in expression of BAX and Bcl-2, tumour-associated pro- and anti-apoptotic factors, indicated that caspase-dependent apoptotic pathways were responsible for pegamotecan cytotoxicity. ${ }^{46}$ To determine the MTD and doselimiting toxicity of pegamotecan, a phase I dose-escalation study was conducted in 27 patients with advanced solid tumours (ClinicalTrials.gov identifier NCT00080002). At the highest administrated dose $\left(4300 \mathrm{mg} \mathrm{m}^{-2}\right)$, one patient had grade 4 gastrointestinal haemorrhage, grade 4 neutropaenia, and grade 3 haematuria and died 4 days later. Additional dose-limiting toxicities included grade 3 toxicities including anaemia, thrombocytopaenia, fatigue, prolonged partial thromboplastic time, haemorrhagic cystitis, dysuria, and urinary frequency in two out of four patients. Haematuria also occurred in eight out of 15 patients at a range of doses. Terminal elimination half-life was at $46 \pm 12.8$ hours and the MTD was determined to be $3240 \mathrm{mg} \mathrm{m}^{-2}$ every week for 3-4 weeks. No confirmed objective responses were detected. Due to the unanticipated high toxicity, a previously published dosing schedule with subjects receiving a higher dose in longer cycles (7000 $\mathrm{mg} \mathrm{m}^{-2}$ every 3 weeks) was advanced instead. ${ }^{45}$ In 2009, phase II study results of second-line pegamotecan monotherapy in patients with advanced and metastatic gastric and gastro-oesophageal junction adenocarcinoma were published. Of the 34 patients who received the recommended dose, the partial response rate was $14.3 \%$ with a median TTP of 11.9 weeks and mOS at 38.1 weeks. Reported grade $3 / 4$ toxicities included neutropaenia, thrombocytopaenia, fatigue, nausea, vomiting, and anorexia. Compared to CPT-11, pegamotecan had favourable pharmacokinetic and toxicity profiles, which made pegamotecan a good candidate for combination therapy. Although no drug-related mortality was reported in this study, genitourinary toxicities persisted in 35\% of patients and microscopic haematuria was observed in $14.2 \%$ of patients. ${ }^{47}$ In 2004, a safety and efficacy phase II study (ClinicalTrials.gov identifier NCT00079950) was conducted in patients with advanced or metastatic soft tissue.

Enzon also developed a PEG-prodrug that is loaded with SN38 (EZN-2208). Since only $3-4 \%$ of an injected dose of CPT- 11 is converted to SN38 in the liver, and $55 \%$ of unconverted CPT-11 is excreted through renal clearance, it has been hypothesized that PEG conjugation would protect the active SN38 and offer antitumour features superior to CPT-11. Preclinical studies showed that EZN-2208 was active against several in vivo tumour models that are resistant to CPT-11 and showed prolonged circulation in the blood and thus longer tumour exposure compared to the free drug. ${ }^{48,49}$ Moreover, EZN-2208 exhibited antitumour activity against TPT-resistant malignant tumours. ${ }^{50}$ A dose-escalation phase I study was conducted to evaluate the safety, tolerability, pharmacokinetics, and activity of EZN-2208 in 39 patients with advanced malignancies (ClinicalTrials.gov identifiers NCT00520637 and NCT00520390). The nanoparticle was infused with or without granulocyte 
colony-stimulating factor (G-CSF) for 1 hour once every 21 days. MTD was determined at $16.5 \mathrm{mg} \mathrm{m}^{-2}$ with G-CSF infusion and $10 \mathrm{mg} \mathrm{m}^{-2}$ without. EZN-2208 was well tolerated and the dose-limiting toxicity was febrile neutropaenia. Adverse effects included fatigue (41\%), alopecia (33\%), diarrhoea (33\%), nausea (33\%), neutropaenia (23\%), and vomiting $(21 \%)$. The nanoparticle achieved a terminal half-life of $19.4 \pm 3.4$ hours. Sixteen patients $(41 \%)$ achieved stable diesease, including $15 \%$ in whom disease was stable for more than 4 months. ${ }^{51}$ Subsequently, a multiarm phase II clinical study has been conducted in second-line treatment of metastatic colon cancer (ClinicalTrials.gov identifier NCT00931840). The first arm was infused with EZN-2208 alone ( $9 \mathrm{mg} \mathrm{m}^{-2}$ on days 1,8 and 15 every 28 days) in 93 patients with KRASmutation. The second and third arms included patients with KRAS wild-type tumour randomised to receive $400 \mathrm{mg} \mathrm{m}^{-2}$ cetuximab (Erbitux ${ }^{\circledR}$; BristolMyers Squibb/Lilly/Merck) in combination with either $9 \mathrm{mg} \mathrm{m}^{-2}$ EZN-2208 (80 patients) or $125 \mathrm{mg} \mathrm{m}^{-2} \mathrm{CPT}-11$ (38 patients). In the KRAS-mutation arm, response rate was $0 \%$ and median progression-free survival (mPFS) was only 1.8 months. In the KRAS-wild-type arms, cetuximab plus CPT-11 or EZN-2208 showed no significant difference in response rate (10.7\% vs. $14.3 \%)$, mPFS (4.9 months vs. 3.7 months) or mOS (9.1 months vs. 9.8 months). EZN-2208 was well tolerated in combination with cetuximab. Grade $3 / 4$ adverse events included neutropaenia (30\% in EZN-2208 alone, 35\% in cetuximab plus EZN-2208, and $16 \%$ in cetuximab plus CPT-11); anaemia (10\% in EZN-2208 alone, 1\% in cetuximab plus EZN-2208, and 13\% in cetuximab plus CPT-11); leukopaenia (8\% in EZN-2208 alon, 9\% in cetuximab plus EZN-2208, and 0\% in cetuximab plus CPT-11); and other non-haematological adverse effects. ${ }^{52}$ Another phase II clinical study has been conducted using EZN-2208 in patients with metastatic breast cancer (ClinicalTrials.gov identifier NCT01036113).

Developed by Nektar Therapeutics, NKTR-102 (etirinotecan pegol) is a polymeric nanoparticle with a proprietary PEG core conjugated to CPT-11 by a biodegradable linker that is slowly hydrolysed to form active SN38. This allows for a continuous exposure to SN38 and thus a prolonged TOP1 inhibition. NKTR-102 entered phase II clinical studies for colorectal cancer, breast cancer, ovarian cancer, and cervical cancer. Awada et al. at the Jules Bordet Institute, Université Libre de Bruxelles (Brussels, Belgium) recently reviewed results from a randomised phase II study of NKTR-102 in patients with second-line metastatic breast cancer (ClinicalTrials.gov identifier NCT00802945). The study included 70 patients randomly divided into two equal groups, where two dosage schedules $\left(145 \mathrm{mg} \mathrm{m}^{-2}\right.$ every 14 days or 21 days) were chosen for treatment. Although results indicated that $29 \%$ of patients achieved an objective response, grade 3 or worse adverse events were reported. On the 14-day dosing schedule, drug-related toxicities led to the discontinuation of $20 \%$ of subjects and caused two possible drug-related deaths (renal failure and septic shock). Therefore, the less toxic 21-day schedule was chosen instead for a subsequent phase III trial in 840 patients with metastatic breast cancer who previously received an anthracycline, a taxane and capecitabine $\left(\right.$ Xeloda $^{\circledR} ;$ Roche) (BEACON trial, 
ClinicalTrials.gov identifier NCT01492101). This phase III has completed and the clinical data did not demonstrate an improvement in overall survival for etirinotecan pegol compared with treatment of physician's choice in patients with pre-treated breast cancer. ${ }^{53-55,151}$ Vergote et al. recently published results from a phase II clinical trial of NKTR-102 in patients with recurrent platinum-resistant/refractory epithelial ovarian cancer (ClinicalTrials.gov identifier NCT00806156). Two dosage schedules (145 $\mathrm{mg} \mathrm{m}^{-2}$ every 14 days or 21 days) were given to 71 eligible patients divided into two groups. The overall response rates (ORR) were $20 \%$ and $19 \%$; mPFS was 4.1 months and 5.3 months, and mOS was 10.0 months and 11.7 months for the 14-day and 21-day schedules, respectively). Grade $3 / 4$ toxicities included dehydration $(24 \%)$ and diarrhoea (23\%), whereas neutropaenia was less frequent $(11.3 \%) .{ }^{56}$ On a side note, the study suggested the use of the TOP1 gene as a biomarker prior to treatment in order to predict sensitively and reduce potential toxicities. ${ }^{53}$ Other NKTR-102 clinical studies include an open-label multicenter extension study of NKTR-102 in subjects previously enrolled in NKTR-102 studies (ClinicalTrials.gov identifier NCT01457118); a phase IIa/IIb multicenter open-label study to evaluate NKTR-102 in combination with cetuximab $v s$. irinotecan in combination with cetuximab in second-line colorectal cancer patients (ClinicalTrials.gov identifier NCT00598975); a phase II study in cancer patients with hepatic impairment to evaluate the pharmacokinetics and safety of NKTR-102 (ClinicalTrials.gov identifier NCT01991678); a phase I study of NKTR-102 in bevacizumab-resistant high grade glioma (ClinicalTrials.gov identifier NCT01663012); a phase II study in patients with relapsed SCLC (ClinicalTrials.gov identifier NCT01876446); a new phase II study in patients with second-line, irinotecan-naïve, KRASmutant colorectal cancer (ClinicalTrials.gov identifier NCT00856375); and a phase II study in NSCLC (ClinicalTrials.gov identifier NCT01773109).

Other polymeric nanoparticle approaches include CPT-loaded poly(DL-lactic acid) and poly(ethylene glycol)-block-poly(propylene glycol)-blockpoly(ethylene glycol) copolymer (PEG-PPG-PEG), which has been shown to enhance the anti-tumour efficacy of CPT. ${ }^{57}$

\subsubsection{Amphiphilic Polymeric Nanoparticles}

In 2004, Zhang et al. at Nanjing University in China described a new family of biodegradable copolymers called poly(caprolactone-co-lactide)- $b$ PEG- $b$-poly(caprolactone- $c o$-lactide) or PCLLA-PEG-PCLLA. This amphiphilic copolymer self-assembles into $70-180 \mathrm{~nm}$ nanoparticles that encapsulate a new CPT derivative 10-hydroxycamptothecin-10,20-diisobutyl dicarbonate or HCPT-1. Depending on copolymer composition and preparation conditions, HCPT-1 loading could achieve up to 7 wt $\%$ and water solubility increased 3000 times compared to the free drug. When dispersed in PBS, free HCPT-1 was rapidly released (up to $30 \%$ was released in the first hour). After 8 hours, HCPT-1 release steadily slowed down. The fast release could be due to the large surface area of the nanoparticle or the low $T_{\mathrm{g}}$ of the hydrophobic core 
of PCLLA-PEG-PCLLA nanoparticles, causing high mobilization of HCPT-1. However, biodistribution analysis showed that HCPT-1 blood concentration was relatively stable after 24 hours of intravenous injection. The highest levels of HCPT-1 accumulation were detected in mouse lung and spleen tissue and low levels were also detected in the kidney and liver. More preclinical studies are needed to verify the pharmacodynamics of this drug. ${ }^{58,59}$

Another interesting approach was taken by a 2010 Korean study at Kyung Hee University using $\mathrm{pH}$-sensitive amphiphilic nanoparticles to encapsulate CPT. The pH-responsive polymeric micelle consisted of hydrophilic methyl ether PEG and $\mathrm{pH}$-responsive poly( $\beta$-amino ester) that copolymerized, self-assembled and encapsulated CPT at neutral conditions ( $\mathrm{pH} 7.4$ ). The nano-sized $(214 \mathrm{~nm})$ particle depolymerizes in response to the tumoural acidic conditions ( $\mathrm{pH}$ 6.4). Amphiphilic nanoparticles with an optimal drug loading of $10 \mathrm{wt} \%$ were shown to passively target breast tumour xenografts and release CPT load in response to a slightly acidic microenvironment. Importantly, antitumour activity was detected and $>70 \%$ of CPT in the lactone ring form could be maintained for 24 hours. Using fluorescence imaging, the pH-PM biodistribution result clearly showed substantial tumour accumulation and an overall favourable pharmacokinetic profile. ${ }^{60}$

\subsubsection{Bioconjugates}

Minko et al. at Rutgers (USA) studied the cytotoxicity and antitumour efficacy of biotinylated PEG-conjugates to CPT. Biotin was included as a moiety to increase intestinal absorption via sodium-dependent multivitamin transporters. In this way CPT cytotoxicity increased up to 60 times in sensitive A2780 and 30 times in A2780/AD multidrug-resistant ovarian cancer cells. In vitro toxicity studies showed that PEG-biotin alone did not cause any cell toxicity and CPT-PEG-biotin induced caspase-dependent apoptosis. ${ }^{61}$

Another novel bioconjugate was described in 2004 used a PEG backbone conjugated to CPT via a glycine linker, and to folic acid via either of its two available carboxylate groups on the distal end. This double conjugation served two purposes. First, CPT water solubility was enhanced without destabilizing its lactone structure. Second, the folic acid could hence mediate tumour-specific endocytosis through the folate receptor, which is overexpressed in human nasopharyngeal carcinoma, for example. Unlike large nanoparticles, the CPT-Gly-PEG-folate conjugate has low molecular weight and thus less immunogenic. ${ }^{62}$

Another CPT-bioconjugate approach used substance $\mathrm{P}$, an 11-residue neuropeptide, to conjugate to CPT to specifically target tumour cells that overexpress neurokinin-1 receptor. This proof-of-concept approach showed selective and strong cytotoxicity across many malignant tumour types, including breast cancer, astrocytoma and glioblastoma. Since substance P is a short peptide, it can be chemically synthesised. Another feature of substance $\mathrm{P}$ is that only C-terminal amino acids are essential for neurokinin-1 receptor-mediated binding and cellular internalization, while the $\mathrm{N}$-terminal 
could be used for CPT conjugation. Similar to other linkers, cysteine amino acid on the N-terminal allowed for proteolytic release of CPT, and aminohexanoic acid was used as a spacer to avoid steric hindrance. However, CPT solubility improved only about 38 times, and when loading of CPT increased, the conjugate solubility worsened. Moreover, both cellular internalization and cytotoxicity could improve when a spacer was used. More preclinical studies are needed to verify the pharmacokinetic and pharmacodynamic feature of this novel drug. Moreover, new formulations should be used to improve its stability, solubility, and cytotoxicity. ${ }^{63}$

Vekhoff et al. described a new generation of CPT conjugates with sequence-specific DNA ligands that enhanced CPT positioning to its binding site on the DNA of target cells. This could be achieved by conjugating a bromoalkyl analogue of gimatecan to the $3^{\prime}$ end of triplex-forming oligonucleotides (TFO). A TFO-gimatecan conjugate proved to be both stable and potent against HeLa cells in vitro. ${ }^{64}$

Other bioconjugate approaches include hyaluronic acid-conjugated CPT-11 (Meditech Research); ${ }^{65}$ transferrin-PEG nanoparticles; ${ }^{66}$ and camptothecin coupled to bombesin analogue. ${ }^{67}$

\subsubsection{Non-polymeric Nanoparticles}

Non-polymeric nanoparticles are listed and reviewed elsewhere. They include IHL-305 CPT-11 liposomes (Yakult Honsha, Japan); ${ }^{68}$ CPX-1 irinotecan-floxuridine liposome; ${ }^{69}$ STEALTH liposomal S-CKD- $602 ;{ }^{70}$ SN38 liposomes from Neopharm $;^{71}$ and NK012 SN38 micelle. $^{72}$

\subsection{Hypoxia Inducible Factor-1 Inhibitors}

HIF-1 is a transcription factor that plays an essential role in the cellular hypoxic response. When activated, its two subunits, HIF- $1 \alpha$ and HIF- $1 \beta$, dimerise and enhance the expression of survival genes. ${ }^{73}$ Genetic analysis revealed that more than 60 putative genes could be direct targets of HIF-1 activation. These target genes fall largely into four categories: angiogenesis, glycolysis, tumour survival, and invasion. Within hypoxic tumour tissue, HIF-1 activation leads to the transcription of target genes responsible for pathophysiological phenotypes such as immortalization, stem cell-like features, dedifferentiation, neo-angiogenesis, invasion, and metastasis. In cancer therapy, HIF-1 $\alpha$ overexpression has been linked to antiangiogenicassociated drug resistance and poor prognosis across several tumour types including breast cancer, ovarian cancer, and gastric cancer ${ }^{74-76}$ Moreover, an important indicator of HIF-1 abnormal activity, carbonic anhydrase-IX (CAIX), is up-regulated in many tumour types and linked to poor prognosis. ${ }^{77-82}$

\subsubsection{ME2}

2-methoxyestradiol (2ME2; Panzem), is a microtubule polymerization inhibitor that has been shown to interact with HIF-1 $\alpha$ and block 
angiogenesis. ${ }^{83}$ In a phase II safety study of orally administrated 2ME2 in patients with homrmone-refractory prostate cancer, the drug was well tolerated in general. However, since pharmacokinetic results also showed low sustainability, ${ }^{84}$ 2ME2 was reformulated as a NanoCrystal ${ }^{\circledR}$ colloidal dispersion (NCD). In a phase II study of 2ME2 NCD in 21 patients with taxanerefractory, metastatic castrate-resistant prostate cancer (ClinicalTrials.org identifier NCT00394810), only 5.35\% reached PFS at 6 months, while the mPFS was 56 days and there was no objective response. Grade $3 / 4$ adverse events were observed in $33 \%$ of patients. However, compared to the free drug, 2ME2 NCD showed favourable pharmacokinetics with 10-20 times higher levels of $2 \mathrm{ME} 2$ and its metabolite $2 \mathrm{ME} 1$ in plasma. ${ }^{85}$ Additionally, a multicenter phase II study was conducted (ClinicalTrials.org identifier NCT00444314) of 2ME2 NCD alone with its combination with sunitinib (Sutent ${ }^{\mathbb{R}}$; Pfizer) in second-line metastatic RCC. Only 12 patients were evaluable in the trial and the study was terminated due to the drug's minimal antitumour activity and high intolerability. New formulations are currently under development. ${ }^{86}$ Other clinical trials with 2ME2 NCD include a phase II study in combination of with bevacizumab (Avastin ${ }^{\mathbb{R}}$; Genentech/Roche) in patients with metastatic carcinoid tumours (ClinicalTrials.org identifier NCT00328497); a phase II study in patients with relapsed or plateau-phase multiple myeloma (ClinicalTrials.org identifier NCT00592579); a phase II study in patients with glioblastoma (ClinicalTrials.org identifier NCT00306618; a phase II study in patients with ovarian cancer (ClinicalTrials.org identifier NCT00400348); and a phase II study in combination with the chemotherapeutic drug temozolomide $\left(\right.$ Temodar $^{\mathrm{R}}$; Merck) in patients with recurrent glioblastoma multiforme (ClinicalTrials.org identifier NCT00481455).

\subsubsection{Camptothecins}

CPT and TPT are also known to inhibit HIF-1 $\alpha$ expression in addition to the TOP1 inhibitory effects described above. CPT derivatives inhibit HIF-1 $\alpha$ expression when administrated daily at low nanomolar concentrations. ${ }^{87}$ Additionally, the presence of CPT under hypoxic conditions have also been shown to down-regulate VEGF expression. ${ }^{88}$

Little is known about how CPT inhibits HIF- $1 \alpha$. A recent paper by Giovanni Capranico and colleagues at the University of Bologna (Italy), suggested a molecular mechanism by which CPT inhibits HIF- $1 \alpha$ activity. ${ }^{89}$ Using microarray analysis, two micro-RNAs (miR-17-5p and miR-155) were identified as CPT-associated suppressors of HIF-1 $\alpha$ protein expression. Moreover, it has been suggested that TPT acts on HIF- $1 \alpha$ through a signalling pathway downstream of TOP1 ${ }^{87}$

Several clinical studies have been conducted to test the therapeutic potential of using CPT derivatives to inhibit HIF-1 in tumour tissue. A phase I study in which oral TPT was administrated in combination with radiotherapy in patients with rectal cancer was conducted in September 2005 (ClinicalTrials.org identifier NCT00215956). A phase I pharmacokinetic 
study of weekly low doses of TPT administrated intravenously in combination with carboplatin and etoposide in patients with extensive stage SCLC was conducted in August 2006 (ClinicalTrials.org identifier NCT00025272). ${ }^{90}$ Another phase I dose-escalation pharmacokinetic study of TPT in combination with erlotinib (Tarceva ${ }^{\circledR}$; Genentech/Roche) in patients with refractory solid tumours was conducted in January 2008 (ClinicalTrials.org identifier NCT00611468).

\subsubsection{SiRNA Technologies}

Using locked nucleic acid technology, Enzon Pharmaceuticals developed a specific HIF-1 $\alpha$ mRNA antagonist (EZN-2968) with durable and potent antitumour effects against human prostate and glioblastoma cell lines. ${ }^{91} \mathrm{~A}$ phase I pilot study of EZN-2968 in patients with advanced solid tumours with liver metastases has been conducted in order to determine the safety and potency of EZN-2968 (ClinicalTrials.org identifier NCT01120288).

Liu et al. from the University of Science and Technology of China recently developed a micellar nanoparticle containing HIF-1 $\alpha$ short interfering (si)RNA, which could block hypoxic tumour growth in prostate cancer xenograft models. ${ }^{92}$

\subsubsection{Endogenous HIF-1 $\alpha$ Inhibitors}

In addition to HIF- $1 \alpha$, two other family members (HIF- $2 \alpha$ and HIF- $3 \alpha$ ) have been identified which alternatively dimerise with HIF-1 $\beta$ and regulate the hypoxic response. ${ }^{93,94}$ Other HIF-1 $\alpha$ endogenous regulators include the von Hippel-Lindau (VHL) tumour suppressor protein, which facilitates its degradation through the ubiquitin pathway. ${ }^{95}$ Other endogenous inhibitors of HIF- $1 \alpha$ are listed in Bao et al. ${ }^{96}$ They include oxygen-sensitive factorinhibition HIF (FIH); p53; phosphatase and tensin homologue (PTEN) and liver kinase B1 (LKB1). Recent studies showed the role of miRNAs in regulating HIF-1 $\alpha$ expression. miR-21 overexpression is associated with high levels of HIF- $1 \alpha$ and VEGF. Hypoxia leads to increased expression of miR-21 in pancreatic and prostate cancer cells. Knocking down miR-21 blocks VEGF expression and the self-renewal capacity of cancer stem cells. miR-107 negatively regulates HIF- $1 \alpha$ and VEGF expression under hypoxic conditions. miR-210 up-regulates VEGF and CAIX in pancreatic cancer through HIF- $1 \alpha$. miR-373 is positively associated with HIF- $1 \alpha$ in hypoxic cells. miR-20 inhibits VEGF and expression through HIF- $1 \alpha$ in hypoxic breast cancer cells. miR-22 has anti-angiogenic effects through down-regulation of HIF- $1 \alpha$ and VEGF expression in tumour tissue. miR-101 expression suppresses the self-renewal capacity of cancer stem cells. ${ }^{96}$

\subsubsection{Other HIF-1 $\alpha$ Inhibitors}

Due to the key role that HIF-1 seems to play in tumour progression, several clinical and preclinical approaches have been taken to pharmaceutically 
modulate HIF-1 pathways or its upstream effectors. Comprehensive reviews of HIF-1 inhibitors can be found in Semenza ${ }^{74}$ and Xia et al., ${ }^{97}$ but we list some here. Developed by Bayer (Germany), BAY87-2243 is a potent HIF-1 $\alpha$ and HIF- $2 \alpha$ inhibitor with antitumour activity. ${ }^{98}$ A phase I clinical study conducted to evaluate the MTD of BAY87-2243 in patients with advanced malignancies (ClinicalTrials.org identifier NCT01297530) was terminated due to unanticipated high toxicities. ${ }^{99}$ Elara Pharmaceuticals (Germany) has developed ELR510444, which is a novel HIF-1 $\alpha$ and HIF- $2 \alpha$ inhibitor that reduced RCC viability in a VHL-independent manner. ELR510444 induced necrosis, apoptosis, and inhibited angiogenesis in 786-O and A498 RCC xenograft models. ${ }^{100}$ Sorafenib (Bay4-9006, Nexavar ${ }^{\mathbb{R}}$; Bayer/Onyx) is a RAF kinase inhibitor that is approved for hepatocellular carcinoma, RCC, and thyroid cancer. Studies also showed that sorafenib had inhibitory effects on HIF-1 activity. ${ }^{101,102}$ Temsirolimus (CCI-779, Torisel ${ }^{\mathbb{R}}$; Pfizer) is an mTOR inhibitor that is approved for RCC. Temsirolimus also inhibited HIF- $1 \alpha$ in human lung cancer cell lines under hypoxic conditions. ${ }^{103}$ A phase I/II clinical trial (ClinicalTrials.gov identifier NCT00329719) is currently under way to evaluate the synergistic effects of combining temsirolimus with sorafenib. Geldanamycin, an HSP-90-specific inhibitor, has been shown to promote HIF-1 $\alpha$ degradation under both hypoxic and normoxic conditions. ${ }^{104}$ Tanespimycin (17-AAG), a derivative of geldanamycin with similar HIF- $1 \alpha$ inhibitory properties is currently being evaluated as both monotherapy and combination therapy with anti-angiogenic agents in patients with multiple myeloma and breast cancer. ${ }^{105}$

Many other small molecules that target HIF- $1 \alpha$ are currently tested preclinically: the Trx-1 inhibitor PX-12 was reported to inhibit HIF-1 activity; ${ }^{106}$ PD98059 is an MEK inhibitor shown to inhibit HIF-1 activity preclinically; ${ }^{107}$ NSC-134754 is a novel small molecule that inhibits HIF- $1 \alpha$ activity and thus inhibits tumour progression. ${ }^{108,109}$ Other inhibitors include pleurotin (1-methylpropyl 2-imidazolyl disulphide), a thioredoxin-1 inhibitor; ${ }^{106}$ YC-1 [3-(5'-hydroxymethyl-2'-furyl)-1-benzyl indazole], a synthetic compound with HIF-1 $\alpha$-inhibitory activity; ${ }^{110,111}$ heteroarylsulfonamides (3,4-dimethoxy$N$-[(2,2-dimethyl-2H-chromen-6-yl)methyl]- $N$-phenylbenzenesulfonamide), a novel HIF- $1 \alpha$ inhibitor tested against human glioma cells; ${ }^{112}$ and cyclic peptide inhibitors of HIF-1. ${ }^{113}$

\subsection{Cancer Stem Cells}

The importance of targeting HIF-1 signalling pathways partly comes from its role in regulating cancer stem cells and its role during epithelialmesenchymal transition. Although induced hypoxia has anti-tumour effects, it enhances the self-renewal capacity and maintenance of the dedifferentiated state of cancer stem cells. Surface marker studies confirmed that hypoxia induces stem cell-like phenotypes and thus leads to tumour aggressiveness and poor prognosis. ${ }^{96}$ Conversely, cancer stem cells use induced hypoxia to protect from DNA damage by reduction of reactive oxygen species. This can be achieved by activating HIF- $1 \alpha$, which is 
preferentially expressed in cancer stem cells compared with other cancer cells in the same tissue. In vivo knockdown studies showed that both HIF-1 $\alpha$ and HIF- $2 \alpha$ are required for cancer stem cell survival and tumour propagation. In fact, knocking down these factors led to reduced tumour formation or inhibited VEGF-mediated angiogenesis. ${ }^{114}$

Other evidence of the role of HIF-1 in cancer stem cell regulation is covered in a review by Sarkar and colleagues at Wayne State University (Detroit, MI, USA). ${ }^{96}$ In brief, activation of HIF-1 enhances the expression of stem cell-associated genes such as Oct4, Nanog, c-Myc, Notch-1, and CD133 pathways. Moreover, factors downstream of HIF-1 such as CAIX can regulate the acidic microenvironment of surrounding cancer stem cells. Clinically, both HIF- $1 \alpha$ and CAIX up-regulation have been associated with poor overall and relapse-free survival. ${ }^{96}$

A paper by Wicha and colleagues at the University of Michigan Comprehensive Cancer Center (Ann Arbor, MI, USA) demonstrated how antiangiogenic therapy with either bevacizumab or sunitinib could increase cancer stem cells in orthotropic breast xenograft models by making tumours more hypoxic, thereby activating HIF- $1 \alpha$. These findings suggest that combining antiangiogenic therapy with inhibitors of HIF- $1 \alpha$ will be an improvement over antiangiogenic therapy alone. ${ }^{115}$

Ambasta et al. described a novel technology that uses twin nanoparticles to target both cancer stem cells and adjacent endothelial cells at the same time. ${ }^{116}$

\subsection{Combination Therapy}

VEGF overexpression under hypoxic conditions was first reported in $1992 .{ }^{117}$ A few years later, HIF-1 activation was linked to VEGF tumour progression. ${ }^{118,119}$ A recent review by Rapisarda and Melillo at the National Cancer Institute (NCI; Bethesda, MD, USA) illustrated how combining antiangiogenic drugs with drugs that target HIF-1 $\alpha$ is likely to be mechanistically synergistic. ${ }^{120}$ Since anti-angiogenic treatment eventually induces hypoxia, it will up-regulate HIF- $1 \alpha$, which in turn will promote tumour survival by turning on pathways involving angiogenesis, cell metabolism, proliferation, differentiation, and cancer invasion and metastasis. Therefore, VEGF inhibitors undo their own effects, so combining antiangiogenic therapy such as bevacizumab with inhibitors of HIF-1 $\alpha$ could have a synergistic effect.

For example, a combination of bevacizumab with metronomic TPT overcame the increase in hypoxia and HIF- $1 \alpha$ induced by bevacizumab alone. This strategy provided superior anti-angiogenic effects, which also resulted in superior anti-tumour activity in a glioblastoma xenograft model. ${ }^{3,121} \mathrm{An}$ other remarkable preclinical study was performed by Kerbel and colleagues at the University of Toronto. They demonstrated that combining pazopanib (Votrient ${ }^{\mathbb{R}}$; GlaxoSmithKline), a VEGF receptor inhibitor, with metronomic TPT, is synergistic and resulted in $100 \%$ survival of the drug combination (but not the individual monotherapies) after 6 months of continuous therapy in an aggressive, metastatic, orthotropic xenograft ovarian model. ${ }^{122}$ 
Two orthotropic ovarian cancer model studies showed that combining pazopanib with metronomic TPT is synergistic and resulted in a significant improvement in survival vs. the individual monotherapies. ${ }^{123}$ Burkitt et al. at the University of Michigan Comprehensive Cancer Center demonstrated that genetic disruption of both HIF- $1 \alpha$ and HIF- $2 \alpha$ had synergistic anti-tumour activity when combined with sunitinib in a colorectal xenograft model. ${ }^{124}$

Clinically, Kummar et al. at the NCI demonstrated that metronomic dosing of TPT inhibited HIF- $1 \alpha$ in patients, and that correlated with antiangiogenics as well, as measured by decreased tumour expression of VEGF and decreased tumour blood flow and permeability. These data validate extensive preclinical data showing that metronomic TOP1 inhibition can inhibit HIF- $1 \alpha$ and important downstream targets of HIF- $1 .^{125}$ Recently, a multicenter phase II trial combining TPT with cisplatin and bevacizumab in recurrent cervical cancer was published (ClinicalTrials.org identifier NCT00548418). Although the study significantly improved mPFS (7.1 months) and mOS (13.2 months), grade $3 / 4$ toxicity was common (thrombocytopaenia $82 \%$, leukopaenia $74 \%$, and anaemia $63 \%$ ) and most patients $(78 \%)$ required unanticipated hospital admission. ${ }^{126}$

The SN38-bearing nanoparticle EZN-2208 (described in Section 8.2.4) has been shown to inhibit HIF- $1 \alpha$ and its downstream targets such as VEGF1 in a U251 glioma xenograft model. ${ }^{127}$ The nanoparticle is currently evaluated for potential HIF-1 inhibition and anti-tumour effects in combination with bevacizumab in patients with refractory tumours (ClinicalTrials.org identifier NCT01251926).

Combining radiotherapy with HIF- $1 \alpha$ inhibition is another frontier under investigation. Inhibition and knockdown of both HIF- $1 \alpha$ and HIF- $2 \alpha$ increased tumour sensitivity to radiotherapy. ${ }^{96}$ A meta-analysis study of more than 4800 patients connected hypoxic modification of radiotherapy and improved therapeutic benefit in patients with head and neck cancer. ${ }^{128}$

Janssen et al. synthesized an RGD-peptide (described in Section 8.2.2) labeled with radioactive Yttrium-90 $\left({ }^{90} \mathrm{Y}\right)$ to target the $\alpha_{\mathrm{v}} \beta_{3}$ integrins on the endothelium associated with OVCAR-3 ovarian tumour xenografts. The radiolabeled peptide showed effective tumour tissue penetration and delayed tumour growth. ${ }^{129}$ A similar approach used RGD-peptide labelled with ${ }^{90} \mathrm{Y}$ and Indium-111 ( $\left.{ }^{111} \mathrm{In}\right) .{ }^{130}$ Other studies demonstrated that HPMAbased nanoparticles (described in Section 8.2.3) could be tagged with ${ }^{90} \mathrm{Y}$ and conjugated to RGD-peptides. ${ }^{131}$ A combination of short-range and longrange particle emitters has been suggested. In this way, emitted alpha particles may have a stronger impact on angiogenesis-associated endothelial cells, while emitted beta particles are ideal for solid tumour irradiation. ${ }^{132}$

\subsection{CRLX101}

CRLX101 (Cerulean Pharma Inc., Cambridge, MA, USA) is a nanopharmaceutical composed of 20-(S)-CPT conjugated to a linear, cyclodextrinPEG-based polymer (CDP). The polymer-drug conjugate self-assembles into 
soluble nanoparticles composed of several conjugate strands when dissolved in aqueous solution. The clinical development of CRLX101 is focused on two unique properties of this nanoparticle, including the ability to increase the circulatory half-life of CPT and the ability to enhance distribution of CPT into tumour tissue for prolonged periods with a low plasma concentration of free CPT. ${ }^{1}$ Given these unique properties, it was hypothesised that CRLX101 could enhance antitumour activity while avoiding the toxicity observed with traditional TOP1 inhibitors.

\subsubsection{CRLX101 Chemistry}

In order to use CRLX101 safely in clinical settings, the de novo design included key features addressing biocompatibility and low toxicity. The backbone of this nanoparticle contains $\beta$-cyclodextrin $(\beta-\mathrm{CD})$, which is a cyclic oligosaccharide consisting of $(\alpha-1,4)$-linked- $\alpha$-D-glucopyranose. $\beta$-CD is copolymerised with difunctionalised polyethylene glycol $\left(\mathrm{PEG}_{3400}\right)$ in order to give a high molecular weight $(>50 \mathrm{kDa})$ polymer. Copolymerising $\beta-\mathrm{CD}$ with $\mathrm{PEG}_{3400}$ serves two main purposes. First, the high molecular weight of $\mathrm{PEG}_{3400}$ creates a relatively long distance between reactive groups and thus minimises the steric hindrance between $\beta$-CD molecules in the construction of polymer chains. Second, $\mathrm{PEG}_{3400}$ plays a key role in avoiding immunorecognition. The large size of CRLX101 also does not allow for first-pass renal clearance, and thus high levels of circulating nanoparticles are maintained. The copolymer-CPT conjugate self-assembles into nanoparticles (30-40 nm) and when dispersed into neutral PBS buffer, their zeta potential is ca. $-2 \mathrm{mV}$. Importantly, CPT solubility increased 1000 -fold after conjugation. Although CDP nanoparticles are not biodegradable, they disassemble into small $(\sim 8 \mathrm{~nm})$ individual CD polymer strands as soon as CPT is released, allowing renal clearance to slowly take place. This unique feature of CRLX101 grants favourable pharmacokinetics with minimal a toxicity profile (Figure 8.2). 1,133,134

Lactone ring stabilisation is a key feature of CRLX101, since CPT is conjugated to the polymer in such a way as to protect the lactone ring from being opened up. CPT is functionalised to form an ester bond at the 20hydroxyl group and a glycine linker was used to provide optimal antitumour efficacy with low toxicity. CPT is conjugated to the carboxylate group on the linear CD polymer while the lactone ring is maintained (Figure 8.3). ${ }^{6,135}$

\subsubsection{CRLX101 Preclinical Results}

Raubitschek et al. at the City of Hope Comprehensive Cancer Center (Duarte, CA, USA) demonstrated that intravenous administration of CRLX101 was tolerable and effective against lymphoma models tested, resulting in significantly prolonged survival of animals compared to CPT-11. The superior efficacy of CRLX101 over CPT-11 was demonstrated to result in part in 


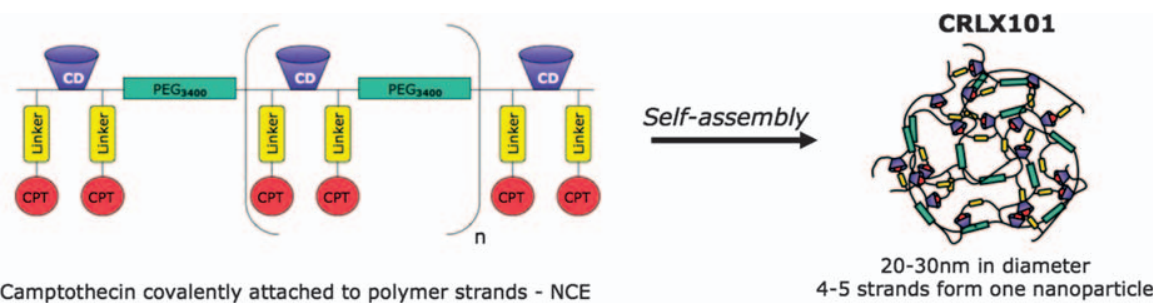

Figure 8.2 Polymer self-assembly of CRLX101 nanoparticles. CRLX101 consists of a potent topoisomerase 1 (TOP1) inhibitor, camptothecin (CPT), conjugated to a poly(ethylene) glycol (PEG)-cyclodextrin copolymer via an ester bond using a glycine linker. CRLX101 self-assembles into $\sim 30 \mathrm{~nm}$ nanoparticles from 4-5 strands of CPT-copolymer conjugate. Strands are held together via guest-host complexes between CPT and cyclodextrin. PEG provides "stealth" against immune recognition, resulting in prolonged circulation of CRLX101. The nanoparticles are large enough to avoid rapid kidney filtration, but small enough to penetrate deep into tumours. CPT is released gradually inside tumour cells, resulting in sustained inhibition of TOP1 and hypoxia-inducible factor (HIF)-1 $\alpha$. CPT is released via chemical hydrolysis; strands come apart and are excreted primarily via the kidney. NCE $=$ new chemical entity.

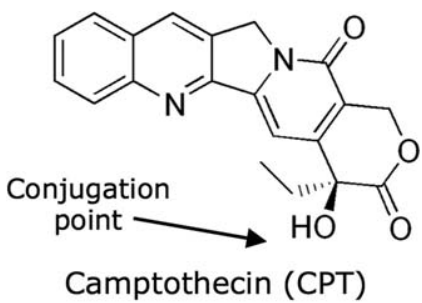

Figure 8.3 Camptothecin chemical structure.

sustained and prolonged concentrations of active drug in lymphoma tumours, which was not achievable with CPT-11. ${ }^{136}$

Davis et al. at California Institute of Technology (Pasadena, CA, USA), demonstrated that CRLX101 has excellent tolerability and anticancer effectiveness in various solid tumour xenografts (NSCLC, SCLC, breast cancer, colon cancer, pancreatic cancer and Ewing's sarcoma). In every case, CRLX101 was demonstrated to be superior to the MTD of CPT-11, and in some models resulted in complete regressions. Three out of the seven models tested were resistant to CPT-11, and striking efficacy of CRLX101 was still observed in these models, demonstrating that CRLX101 can work even in resistant models. ${ }^{137}$ In a pharmacokinetic and biodistribution study performed by the same group, intravenous administration of CRLX101 in rats and tumour-bearing mice resulted in prolonged plasma half-life and enhanced distribution to tumour tissue when compared to CPT alone. Moreover, the tumour concentration of active CPT was 160-fold higher after administration of polymer-bound CPT compared to the administration CPT alone. 
These effects likely play a significant role in the enhanced antitumour activity of CRLX101 when compared to CPT alone or CPT-11. ${ }^{138}$

Notably, CRLX101 tumour growth inhibition of squamous and nonsquamous NSCLC was superior to approved therapeutic agents such as TPT, docetaxel (Taxotere ${ }^{\circledR}$; Aventis), erlotinib (Tarceva ${ }^{\circledR}$ ), gemcitabine (Gemzar ${ }^{\circledR}$; Lilly) and carboplatin (Paraplatin ${ }^{\circledR}$; Bristol-Myers Squibb). Thanks to its sustained levels within penetrated tumour tissue, CRLX101 inhibited cell proliferation uniformly. Moreover, CRLX101 effectively inhibited tumour growth and increased survival in both KRAS-driven and epithelial growth factor receptor (EGFR)-driven mutation models suggesting that CRLX101 can be effective against drug-resistant NSCLC tumours. ${ }^{139}$

Furthermore, multi-organ pharmacokinetics and accumulation in tumour tissue of CRLX101 were investigated using positron emission tomography in tumour-bearing mice. Tumour vascular permeability was calculated and the data indicated that the majority of nanoparticles stay intact in circulation and do not disassemble into individual polymer strands. Histological measurements using confocal microscopy and transmission electron microscopy (Figure 8.4) showed that CRLX101 localises within tumour cells and provides the sink in the tumour for the nanoparticles. ${ }^{140}$ Similar results using serial diffusion magnetic resonance imaging showed a remarkable lymphoma tissue penetration and early treatment response in mice treated with CRLX101 compared to free CPT-11. ${ }^{141}$

In collaboration with Max Wicha at the University of Michigan and others at the University of Pennsylvania and Massachusetts General Hospital,

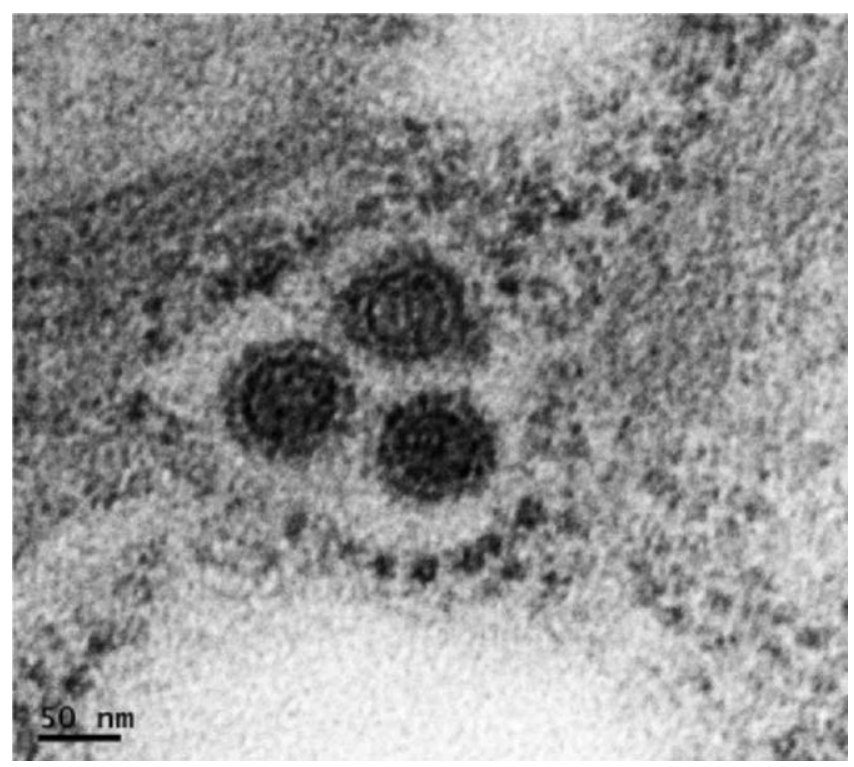

Figure 8.4 Transmission electron microscope image of CRLX101 nanoparticles in a xenograft tumour cell. 
Eliasof et al. at Cerulean Pharma Inc. demonstrated recently that the combination of CRLX101 with antiangiogenic therapeutics have synergistic antitumour properties. CRLX101, through sustained release of its CPT payload, showed a durable HIF- $1 \alpha$ inhibition in multiple human tumour xenograft models including highly metastatic ovarian tumours. These promising results encouraged investigators to study the effects of combining CRLX101 with conventional antiangiogenics. As expected, elevated levels of HIF- $1 \alpha$ associated with bevacizumab, aflibercept (Zaltrap ${ }^{\circledR}$; Sanofi) and pazopanib treatments were significantly suppressed when combined with CRLX101. HIF-1 $\alpha$ inhibition by CRLX101 was not only sustained for 2 weeks, but substantial tumour growth inhibition was also achieved. Similar synergistic effects were observed with radiation therapy in a head and neck xenograft tumour model. Moreover, confocal microscopic imaging showed that HIF-1 $\alpha$ was translocated into the nucleus after CRLX101 treatment. At the cancer stem cell level, CRLX101 prevented the bevacizumab-induced HIF- $1 \alpha$ expression and inhibited tumour regrowth of triple negative breast cancer cells implicating an effective targeting of cancer stem cells. ${ }^{7}$

\subsubsection{CRLX101 Clinical Results}

In an initial phase I/IIa dose-finding, safety, and pharmacokinetic study of CRLX101 in patients with advanced solid tumours, a total of 62 patients were enrolled and treated (ClinicalTrials.gov identifier NCT00333502). The MTD was determined to be $15 \mathrm{mg} \mathrm{m}^{-2}$ on days 1 and 15 of a 28-day cycle. Haematologic toxicity, including neutropaenia, thrombocytopaenia, anaemia, and leucopaenia, was dose-limiting at $18 \mathrm{mg} \mathrm{m}^{-2}$ administered on a weekly schedule, and thrombocytopaenia and neutropaenia were also doselimiting at $18 \mathrm{mg} \mathrm{m}^{-2}$ on an every-other-week schedule. In addition, cystitis, which is an expected toxicity for this drug class, was dose-limiting in a weekly dosing schedule evaluated in phase I. Hydration before and following CRLX101 administration was added to the protocol to mitigate the potential for cystitis. In the phase IIa expansion, 38 patients were enrolled and treated at the established MTD and the MTD appeared to be safe and well tolerated for up to six or more treatment cycles, with the majority of adverse events being grade 1 or 2 . The most common of these were fatigue, cystitis, nausea, anaemia, dysuria, haematuria, and neutropaenia. There were no treatmentrelated deaths, and eight patients, including five treated at the MTD, experienced treatment-related serious adverse events. Three patients experienced serious infusion-related hypersensitivity reactions, leading to amendment of the protocol to include pretreatment with a corticosteroid, an antihistamine, and an $\mathrm{H} 2$ antagonist to minimise infusion-related hypersensitivity reactions. Following intravenous administration of CRLX101 at 6, 12,15 , and $18 \mathrm{mg} \mathrm{m}^{-2}$ in study CRLX-001, systemic plasma exposure to both polymer-conjugated and unconjugated CPT was observed in all subjects. Pharmacokinetic analysis demonstrated exposure that is generally proportional to dose and prolonged plasma exposure that is heavily weighted to 
nanoparticle-conjugated CPT. CRLX101 plasma concentrations increased sharply following intravenous infusion, whereas unconjugated CPT plasma concentrations increased gradually, consistent with slow release of CPT from the polymer conjugate. Clearance and volume of distribution values for the conjugated CPT were dose-independent and suggest this material was retained within the vasculature and highly perfused tissues. The majority of subjects receiving CRLX101 every other week at $15 \mathrm{mg} \mathrm{m}^{-2}$ or $18 \mathrm{mg} \mathrm{m}^{-2}$ had measureable levels of unconjugated CPT in plasma at 14 days post-CRLX101 administration, indicating that in order to avoid significant carry-over of unconjugated plasma CPT from one dose to the next, a dosing interval greater than 1 week is required. Therefore, all subsequent clinical studies were performed with an every-other-week schedule. , $^{8142,143}$

A phase II monotherapy evaluation of CRLX101 include a multisite, multi-country comparison of CRLX101 to best supportive care in NSCLC. Enrolment in this trial is complete and patients remain on study (ClinicalTrials.gov identifier NCT01380769). In March 2013, Cerulean Pharma announced that the phase II NSCLC clinical study did not meet its primary efficacy endpoints and overall survival benefits. ${ }^{144}$ Multiple phase II evaluations of CRLX101 are still active to date.

\subsection{Conclusion}

Preclinical testing of CRLX101 in monotherapy in multiple xenograft models (NSCLC, squamous NSCLC, KRAS mutant NSCLC, EGFR mutant NSCLC, SCLC, ovarian cancer, colorectal cancer, gastric cancer, CPT-11-resistant breast cancer, RCC, pancreatic cancer, and lymphoma) has demonstrated superiority of CRLX101 over every commercial comparator drug tested. In these models, the commercial drugs were administered at their respective optimal dose and dosing schedule and measured for median survival, tumour shrinkage, and tumour growth delay. In many models CRLX101 achieved complete tumour eradication and cure, unattainable with the commercial drugs tested in these models. CRLX101 has also been shown to be a radiosensitiser in an animal model of head and neck cancer, suggesting that CRLX101 may achieve clinical utility in combination with radiotherapy. ${ }^{6,134}$

It has further been demonstrated in preclinical studies that CRLX101 is a potent and durable inhibitor of HIF-1 $\alpha_{0}^{7,149}$ The camptothecin family of compounds (including CPT and TPT) have been described as inhibitors of HIF- $1 \alpha$ in the past. However, the literature suggests that to achieve durable inhibition of HIF- $1 \alpha$, sustained concentrations of TPT must be delivered to cells. Due to its short half-life, low tumour targeting, and high toxicities, TPT cannot effectively achieve durable HIF- $1 \alpha$ suppression. ${ }^{125}$ HIF- $1 \alpha$, which is up-regulated under hypoxic conditions in the tumour microenvironment, has recently become a target of increasing interest in cancer research as it appears to be a master regulator for many key cancer cell survival pathways. ${ }^{74,76,150}$ It is hypothesised that simultaneous inhibition of TOP1 and HIF- $1 \alpha$ by CRLX101 could lead to notable clinical benefit, particularly 
when the nanopharmaceutical is combined with anti-cancer therapies such as VEGF receptor inhibitors, which are known to create hypoxia and up-regulate HIF-1 $\alpha$. In preclinical models, CRLX101 is demonstrated not only to inhibit HIF- $1 \alpha$, but also to achieve synergistic activity in combination with bevacizumab and other VEGF receptor inhibitors, including the tyrosine kinase inhibitor pazopanib and the VEGF trap molecule aflibercept. ${ }^{7}$

In several animal models, the combination of CRLX101 and leading antiangiogenesis drugs demonstrate the following: (1) HIF-1 $\alpha$ protein expression in each case is significantly up-regulated in the presence of each of the tested anti-angiogenesis drugs; (2) HIF-1 $\alpha$ protein expression is significantly down-regulated when exposed to a low dose of CRLX101; (3) when CRLX101 is combined with anti-angiogenesis drugs, HIF- $1 \alpha$ protein expression is down-regulated compared to control, confirming that the CRLX101 downregulation can counteract the up-regulation normally produced by these anti-angiogenesis drugs; and (4) the combination of a low dose of CRLX101 with anti-angiogenesis drugs is synergistic, resulting in markedly longer animal survival than either drug by itself., ${ }^{7,130}$

Similar results have been observed in the preclinical assessment of the nanopharmaceutical's effect on cancer stem cells that cause cancer heterogeneity, drug resistance and metastases. Findings here include: (1) pretreatment with CRLX101 leads to a reduction in cancer stem cells expansion compared to control; (2) pretreatment with bevacizumab leads to enhanced cancer stem cells expansion compared to control; and (3) pretreatment with a combination of CRLX101 and bevacizumab leads to reduced cancer stem cell expansion compared to CRLX101 treatment alone, demonstrating CRLX101's ability to overcome the HIF-1 $\alpha$-associated and undesirable cancer stem cells. ${ }^{149}$

More than 200 human cancer patients have now been treated with CRLX101 in phase I/IIa and phase II clinical trials. In addition to the completed clinical trials, other monotherapy studies of CRLX101 are still running. They include a multi-site randomised phase II clinical trial of 112 patients comparing CRLX101 monotherapy to TPT in advanced small cell lung cancer, or SCLC, conducted at the University of Chicago (Chicago, IL, USA) and at other major medical centres in the USA (ClinicalTrials.gov identifier NCT01803269). The study objectives are to establish feasibility of enrolling this advanced patient population, and differentiate the safety and efficacy of CRLX101 at $15 \mathrm{mg} \mathrm{m}^{-2}$ dosed every 2 weeks $v s$. TPT, the only approved second-line SCLC agent. The first patient was enrolled in January $2013 .{ }^{145}$ A multisite single-arm phase II clinical trial in advanced ovarian cancer patients in monotherapy is conducted at the Massachusetts General Hospital, Brigham and Women's Hospital, Dana-Farber Cancer Center, and Beth Israel Deaconess Medical Center (Boston, MA, USA) (ClinicalTrials.gov identifier NCT01652079). The objectives of this trial are to establish activity worthy of further investigation based on predefined criteria and to confirm safety and tolerability of CRLX101 at $15 \mathrm{mg} \mathrm{m}^{-2}$ dosed every 2 weeks in ovarian cancer patients. The first patient was enrolled in June 2012 and 
enrolment is now complete with patients remaining on study at this time. ${ }^{146}$ A single-arm phase II pharmacodynamic clinical trial in advanced human epithelilal growth receptor 2 (HER2)-negative gastric cancer patients at the City of Hope National Comprehensive Cancer Center (ClinicalTrials.gov identifier NCT01612546). This study's objectives are to establish signals of activity in HER2-negative gastric cancer patients and to utilise sequential tumour biopsies to establish differential nanopharmaceutical tumour penetration. The first patient was enrolled in December 2012 and enrolment continues.

Combination therapy evaluations of CRLX101 include a single-arm phase II clinical trial in advanced RCC patients of CRLX101 at $15 \mathrm{mg} \mathrm{m}^{-2}$ dosed every 2 weeks in combination with bevacizumab $\left(10 \mathrm{mg} \mathrm{kg}^{-1}\right.$ every 2 weeks) conducted at the University of Pennsylvania (Philadelphia, PA, USA) (ClinicalTrials.gov identifier NCT01625936). After establishing combinability of CRLX101 at the MTD (phase Ib), the objectives for this trial are to fulfil the predefined efficacy criteria of the combination, supporting further evaluation of the combination in RCC. The first patient was enrolled in June 2012 and enrolment is continuing. Very recent results showed that ORR was $30 \%$ and mPFS was 7.9 months, which is better than benchmarks such as everolimus (Afinitor ${ }^{\circledR}$; Novartis) (ORR 4\%; mPFS 4.7 months or less). ${ }^{147,148}$ A multisite single-arm phase II clinical trial in advanced ovarian cancer patients of CRLX101 at $15 \mathrm{mg} \mathrm{m} \mathrm{m}^{-2}$ dosed every 2 weeks in combination therapy with bevacizumab $\left(10 \mathrm{mg} \mathrm{kg}^{-1}\right.$ every 2 weeks) conducted at the Massachusetts General Hospital, Brigham and Women's Hospital, DanaFarber Cancer Center, and Beth Israel Deaconess Medical Center. The objectives of this trial are to establish activity worthy of further investigation based on pre-defined criteria and to confirm safety and tolerability of CRLX101 in combination with bevacizumab in patients with ovarian cancer. A two-stage design is being employed to enrol a maximum of 43 women. During Stage I, 18 women will be enrolled and if two or fewer achieve PFS through six cycles of therapy (PFS6), the trial will be terminated. Otherwise, a stage II trial will enrol 25 additional women and if, ultimately, eight or more patients achieve PFS6, the combination will be considered worthy of further investigation. CRLX101 is under investigation in two combination treatments for relapsed ovarian cancer. A Phase 2 trial of CRLX101 plus bevacizumab (Avastin ${ }^{\circledR}$ ) is enrolling patients, and a Phase 1b trial of CRLX101 plus weekly paclitaxel (Taxol) has enrolled patients. ${ }^{149}$

An additional clinical trial evaluating CRLX101 in combination with chemoradiotherapy (CRT) in the neo-adjuvant treatment of rectal cancer is about to commence enrolment at the University of North Carolina Chapel Hill and affiliated centres in the USA (ClinicalTrials.gov identifier NCT02010567). Radiotherapy causes DNA strand breaks which, if not repaired, lead to desired apoptosis of radiated tumour cells. However, cell repair mechanisms, including TOP1, which re-ligates DNA strand breaks, can undo the radiation damage to tumour cells, thus interfering with the desired effects of the radiation therapy. Since TOP1 is instrumental in repairing radiation-induced DNA single strand breaks, a combinable TOP1 
inhibitor is hypothesised to be effective as a radiosensitiser. In fact, combinations of CPT-11 and CRT have shown synergy, raising pathological complete response rates in this setting across various trials. However, the toxicity of CPT-11 prevents its addition to this treatment regimen. CRLX101 in combination with radiotherapy in a head and neck cancer animal model demonstrates notable synergy and radiosensitivity. In addition, hypoxia is a by-product of radiotherapy and there is a well-documented role of hypoxiamediated HIF-1 $\alpha$ induced up-regulation in the induction of resistance to radiotherapy. Accordingly, it is hypothesised that CRLX101, building on both its anti-TOP1 and anti-HIF- $1 \alpha$ activity, as well as its favourable safety profile, offers strong potential as an add-on drug to standard of care CRT in neoadjuvant rectal cancer. This open-label, single-arm phase Ib/II study is designed to identify the MTD/recommended phase II dose of CRLX101 administered in combination with capecitabine-based CRT and to detect signals of increased efficacy over CRT alone. The trial is designed to enrol up to 53 patients, with a primary endpoint of pathological complete response and secondary endpoints of disease-free survival and mOS. ${ }^{7,149}$

\section{References}

1. M. E. Davis, Adv. Drug Delivery Rev., 2009, 61, 1189-1192.

2. A. Lorence and C. L. Nessler, Phytochemistry, 2004, 65, 2735-2749.

3. A. Rapisarda, J. Zalek, M. Hollingshead, T. Braunschweig, B. Uranchimeg, C. A. Bonomi, S. D. Borgel, J. P. Carter, S. M. Hewitt, R. H. Shoemaker and G. Melillo, Cancer Res., 2004, 25, 6845-6848.

4. E. K. Rowinsky, L. B. Grochow, C. B. Hendricks, D. S. Ettinger, A. A. Forastiere, L. A. Hurowitz, W. P. McGuire, S. E. Sartorius, B. G. Lubejko and S. H. Kaufmann, Phase I and pharmacologic study of topotecan: a novel topoisomerase I inhibitor., 1992, vol. 10.

5. H. Hochster, L. Liebes, J. Speyer, J. Sorich, B. Taubes, R. Oratz, J. Wernz, A. Chachoua, B. Raphael and R. Z. Vinci, Phase I trial of low-dose continuous topotecan infusion in patients with cancer: an active and welltolerated regimen., 1994, vol. 12.

6. S. Svenson, M. Wolfgang, J. Hwang, J. Ryan and S. Eliasof, J. Controlled Release, 2011, 153, 49-55.

7. S. Eliasof, S. Conley, S. M. Keefe, R. Kerbel, N. Carolyn, D. Lazarus, C. Peters, E. Pham, M. S. Wicha, E. G. Garmey and C. Pharma, Am. Assoc. Cancer Res., 2013, B1, 95-96.

8. G. J. Weiss, J. Chao, J. D. Neidhart, R. K. Ramanathan, D. Bassett, J. a Neidhart, C. H. J. Choi, W. Chow, V. Chung, S. J. Forman, E. Garmey, J. Hwang, D. L. Kalinoski, M. Koczywas, J. Longmate, R. J. Melton, R. Morgan, J. Oliver, J. J. Peterkin, J. L. Ryan, T. Schluep, T. W. Synold, P. Twardowski, M. E. Davis and Y. Yen, Invest. New Drugs, 2013, 31, 986-1000.

9. M. E. Wall, M. C. Wani, C. E. Cook, K. H. Palmer, A. T. McPhail and G. A. Sim, J. Am. Chem. Soc., 1966, 88, 3888-3890. 
10. Y. H. Hsiang, R. Hertzberg, S. Hecht and L. F. Liu, J. Biol. Chem., 1985, 260, 14873-14878.

11. C. G. Moertel, a J. Schutt, R. J. Reitemeier and R. G. Hahn, Cancer Chemother. Rep., 1972, 56, 95-101.

12. R. P. Hertzberg, M. J. Caranfa, K. G. Holden, D. R. Jakas, G. Gallagher, M. R. Mattern, S. Mong, J. O. L. Bartus, R. K. Johnson and W. D. Kingsbury, J. Med. Chem., 1989, 32, 715-720.

13. Z. Mi and T. G. Burke, Biochemistry, 1994, 33, 10325-10336.

14. R. Garcia-Carbonero and J. G. Supko, Clin. Cancer Res., 2002, 8, 641-661.

15. G. Pratesi, M. De Cesare, N. Carenini, P. Perego, C. Pisano, S. Penco, P. Carminati, L. Vesci and F. Zunino, Clin. Cancer Res., 2002, 3904-3909.

16. C. Pisano, M. De Cesare, G. L. Beretta, V. Zuco, G. Pratesi, S. Penco, L. Vesci, R. Foderà, F. F. Ferrara, M. B. Guglielmi, P. Carminati, S. Dallavalle, G. Morini, L. Merlini, A. Orlandi and F. Zunino, Mol. Cancer Ther., 2008, 7, 2051-2059.

17. S. Dallavalle, S. Gattinoni, S. Mazzini, L. Scaglioni, L. Merlini, S. Tinelli, G. L. Beretta and F. Zunino, Bioorg. Med. Chem. Lett., 2008, 18, 1484-1489.

18. L. Scaglioni, S. Mazzini, R. Mondelli, S. Dallavalle, S. Gattinoni, S. Tinelli, G. L. Beretta, F. Zunino and E. Ragg, Bioorg. Med. Chem., 2009, 17, 484-491.

19. S. Cananzi, L. Merlini, R. Artali, G. L. Beretta, N. Zaffaroni and S. Dallavalle, Bioorg. Med. Chem., 2011, 19, 4971-4984.

20. R. Cincinelli, L. Musso, S. Dallavalle, R. Artali, S. Tinelli, D. Colangelo, F. Zunino, M. De Cesare, G. L. Beretta and N. Zaffaroni, Eur. J. Med. Chem., 2013, 63, 387-400.

21. J. W. Singer, R. Bhatt, J. Tulinsky, K. R. Buhler, E. Heasley, P. Klein and P. de Vries, J. Controlled Release, 2001, 74, 243-247.

22. Y. Matsumura and H. Maeda, Cancer Res., 1986, 46, 6387-6392.

23. A. V. Yurkovetskiy and R. J. Fram, Adv. Drug Delivery Rev., 2009, 61, 1193-1202.

24. E. a. Sausville, L. Garbo, G. J. Weiss, D. Shkolny, a. V. Yurkovetskiy, C. Bethune, R. K. Ramanathan and R. J. Fram, Mol. Cancer Ther., 2009, 8, B52-B52.

25. Y. Ochi, Y. Shiose, H. Kuga and E. Kumazawa, Cancer Chemother. Pharmacol., 2005, 55, 323-332.

26. Y. Shiose, Y. Ochi, H. Kuga, F. Yamashita and M. Hashida, Biol. Pharm. Bull., 2007, 30, 2365-2370.

27. M. Harada, H. Sakakibara, T. Yano, T. Suzuki and S. Okuno, J. Controlled Release, 2000, 69, 399-412.

28. M. Harada, J. Imai, S. Okuno and T. Suzuki, J. Controlled Release, 2000, 69, 389-397.

29. S. Okuno, M. Harada, T. Yano, S. Yano, S. Kiuchi, N. Tsuda, Y. Sakamura, J. Imai, T. Kawaguchi and K. Tsujihara, Cancer Res., 2000, 60, 2988-2995.

30. M. Harada, J. Murata, Y. Sakamura, H. Sakakibara, S. Okuno and T. Suzuki, J. Controlled Release, 2001, 71, 71-86. 
31. R. Bhatt, P. de Vries and J. Tulinsky, J. Med. Chem., 2003, 46, 190-193.

32. Y. Zou, Q. Wu, W. Tansey, D. Chow, M. Hung, C. Charnsangavej, S. Wallace and C. Li, Int. J. Oncol., 2001, 18, 11172600.

33. J. Homsi, G. R. Simon, C. R. Garrett, G. Springett, R. De Conti, A. A. Chiappori, P. N. Munster, M. K. Burton, S. Stromatt, C. Allievi, P. Angiuli, A. Eisenfeld, D. M. Sullivan and A. I. Daud, Clin. Cancer Res., 2007, 13, 5855-5861.

34. S. Dallavalle, G. Giannini, D. Alloatti, A. Casati, E. Marastoni, L. Musso, L. Merlini, G. Morini, S. Penco, C. Pisano, S. Tinelli, M. De Cesare, G. Beretta and F. Zunino, J. Med. Chem., 2006, 49, 5177-5186.

35. A. Dal Pozzo, M.-H. Ni, E. Esposito, S. Dallavalle, L. Musso, A. Bargiotti, C. Pisano, L. Vesci, F. Bucci, M. Castorina, R. Foderà, G. Giannini, C. Aulicino and S. Penco, Bioorg. Med. Chem., 2010, 18, 64-72.

36. R. Duncan, Adv. Drug Delivery Rev., 2009, 61, 1131-1148.

37. V. R. Caiolfa, M. Zamai, A. Fiorino, E. Frigerio, C. Pellizzoni, R. D'Argy, A. Ghiglieri, M. G. Castelli, M. Farao, E. Pesenti, M. Gigli, F. Angelucci and A. Suarato, J. Controlled Release, 2000, 65, 105-119.

38. G. Chirico, M. Collini, F. Olivini, M. Zamai, E. Frigerio and V. R. Caiolfa, Biophys. Chem., 2004, 110, 281-295.

39. D. Bissett, J. Cassidy, J. S. de Bono, F. Muirhead, M. Main, L. Robson, D. Fraier, M. L. Magnè, C. Pellizzoni, M. G. Porro, R. Spinelli, W. Speed and C. Twelves, Br. J. Cancer, 2004, 91, 50-55.

40. F. M. Wachters, H. J. M. Groen, J. G. Maring, J. a Gietema, M. Porro, H. Dumez, E. G. E. de Vries and a T. van Oosterom, Br. J. Cancer, 2004, 90, 2261-2267.

41. F. F. Davis, Adv. Drug Delivery Rev., 2002, 54, 457-458.

42. F. M. Veronese and J. M. Harris, Adv. Drug Delivery Rev., 2002, 54, 453-456.

43. R. B. Greenwald, A. Pendri, C. Conover, C. Gilbert and R. Yang, J. Med. Chem., 1996, 1938-1940.

44. R. B. Greenwald, A. Pendri, C. D. Conover, C. Lee, Y. H. Choe, C. Gilbert, A. Martinez, J. Xia, D. Wu and M. Hsue, Bioorg. Med. Chem., 1998, 6, 551-562.

45. E. K. Rowinsky, J. Rizzo, L. Ochoa, C. H. Takimoto, B. Forouzesh, G. Schwartz, L. A. Hammond, A. Patnaik, J. Kwiatek, A. Goetz, L. Denis, J. McGuire and A. W. Tolcher, J. Clin. Oncol., 2003, 21, 148-157.

46. D. Yu, P. Peng, S. S. Dharap, Y. Wang, M. Mehlig, P. Chandna, H. Zhao, D. Filpula, K. Yang, V. Borowski, G. Borchard, Z. Zhang and T. Minko, J. Controlled Release, 2005, 110, 90-102.

47. L. C. Scott, J. C. Yao, a B. Benson, a L. Thomas, S. Falk, R. R. Mena, J. Picus, J. Wright, M. F. Mulcahy, J. a Ajani and T. R. J. Evans, Cancer Chemother. Pharmacol., 2009, 63, 363-370.

48. P. Sapra, H. Zhao, M. Mehlig, J. Malaby, P. Kraft, C. Longley, L. M. Greenberger and I. D. Horak, Clin. Cancer Res., 2008, 14, 1888-1896.

49. H. Zhao, B. Rubio, P. Sapra, D. Wu, P. Reddy, P. Sai, A. Martinez, Y. Gao, Y. Lozanguiez, C. Longley, L. M. Greenberger and I. D. Horak, Bioconjugate Chem., 2008, 19, 849-859. 
50. S. A. L. Zander, W. Sol, L. Greenberger, Y. Zhang, O. van Tellingen, J. Jonkers, P. Borst and S. Rottenberg, PLoS One, 2012, 7, e45248.

51. R. Kurzrock, S. Goel, J. Wheler, D. Hong, S. Fu, K. Rezai, S. K. MorganLinnell, S. Urien, S. Mani, I. Chaudhary, M. H. Ghalib, A. Buchbinder, F. Lokiec and M. Mulcahy, Cancer, 2012, 118, 6144-6151.

52. C. R. Garrett, T. S. Bekaii-Saab, T. Ryan, G. a Fisher, S. Clive, P. Kavan, E. Shacham-Shmueli, A. Buchbinder and R. M. Goldberg, Cancer, 2013, 119, 4223-4230.

53. D. L. Nielsen and N. Brünner, Lancet Oncol., 2013, 14, 1149-1151.

54. A. Awada, A. a Garcia, S. Chan, G. H. M. Jerusalem, R. E. Coleman, M. T. Huizing, A. Mehdi, S. M. O’Reilly, J. T. Hamm, P. J. Barrett-Lee, V. Cocquyt, K. Sideras, D. E. Young, C. Zhao, Y. L. Chia, U. Hoch, A. L. Hannah and E. a Perez, Lancet Oncol., 2013, 14, 1216-1225.

55. A. Awada, S. Chan, G. H. M. Jerusalem, R. E. Coleman, M. T. Huizing, A. Mehdi, S. M. O'Reilly, J. T. Hamm, P. J. Barrett-Lee, V. Cocquyt, K. Sideras, D. E. Young, M. Brown, C. Zhao, A. L. Hannah, L. K. Masuoka, A. a Garcia and E. a Perez, Am. Soc. Clin. Oncol., 2011, 1, 102.

56. I. B. Vergote, A. Garcia, J. Micha, C. Pippitt, J. Bendell, D. Spitz, N. Reed, G. Dark, P. M. Fracasso, E. N. Ibrahim, V. a Armenio, L. Duska, C. Poole, C. Gennigens, L. Y. Dirix, A. C. F. Leung, C. Zhao, R. SoufiMahjoubi and G. Rustin, J. Clin. Oncol., 2013, 31, 4060-4066.

57. R. Kunii, H. Onishi and Y. Machida, Eur. J. Pharm. Biopharm., 2007, 67, 9-17.

58. L. Zhang, Y. Hu, X. Jiang, C. Yang, W. Lu and Y. H. Yang, J. Controlled Release, 2004, 96, 135-148.

59. L. Zhang, M. Yang, Q. Wang, Y. Li, R. Guo, X. Jiang, C. Yang and B. Liu, J. Controlled Release, 2007, 119, 153-162.

60. K. H. Min, J.-H. Kim, S. M. Bae, H. Shin, M. S. Kim, S. Park, H. Lee, R.-W. Park, I.-S. Kim, K. Kim, I. C. Kwon, S. Y. Jeong and D. S. Lee, J. Controlled Release, 2010, 144, 259-266.

61. T. Minko, P. V. Paranjpe, B. Qiu, A. Lalloo, R. Won, S. Stein and P. J. Sinko, Cancer Chemother. Pharmacol., 2002, 50, 143-150.

62. P. V. Paranjpe, Y. Chen, V. Kholodovych, W. Welsh, S. Stein and P. J. Sinko, J. Controlled Release, 2004, 100, 275-292.

63. W. Zhang, J. Song, L. Mu, B. Zhang, L. Liu, Y. Xing, K. Wang, Z. Li and R. Wang, Bioorg. Med. Chem. Lett., 2011, 21, 1452-1455.

64. P. Vekhoff, L. Halby, K. Oussedik, S. Dallavalle, L. Merlini, C. Mahieu, A. Lansiaux, C. Bailly, A. Boutorine, C. Pisano, G. Giannini, D. Alloatti and P. B. Arimondo, Bioconjugate Chem., 2009, 20, 666-672.

65. K. Y. Choi, H. Y. Yoon, J.-H. Kim, S. M. Bae, R.-W. Park, Y. M. Kang, I.-S. Kim, I. C. Kwon, K. Choi, S. Y. Jeong, K. Kim and J. H. Park, ACS Nano, 2011, 5, 8591-8599.

66. M. Hong, S. Zhu, Y. Jiang, G. Tang, C. Sun, C. Fang, B. Shi and Y. Pei, J. Controlled Release, 2010, 141, 22-29.

67. L.-C. Sun, J. Luo, V. L. Mackey, J. a Fuselier and D. H. Coy, Anticancer. Drugs, 2007, 18, 341-348. 
68. J. R. Infante, V. L. Keedy, S. F. Jones, W. C. Zamboni, E. Chan, J. C. Bendell, W. Lee, H. Wu, S. Ikeda, H. Kodaira, M. L. Rothenberg and H. A. Burris III, Cancer Chemother. Pharmacol., 2012, 70, 699-705.

69. G. Batist, K. A. Gelmon, K. N. Chi, W. H. Miller, S. K. L. Chia, L. D. Mayer, C. E. Swenson, A. S. Janoff, and A. C. Louie, Safety, pharmacokinetics, and efficacy of CPX-1 liposome injection in patients with advanced solid tumors., 2009, vol. 15.

70. W. C. Zamboni, S. Strychor, E. Joseph, D. R. Walsh, B. A. Zamboni, R. A. Parise, M. E. Tonda, N. Y. Yu, C. Engbers and J. L. Eiseman, Clin. Cancer Res., 2007, 13, 7217-7223.

71. J. Williams, R. Lansdown, R. Sweitzer, M. Romanowski, R. LaBell, R. Ramaswami and E. Unger, J. Controlled Release, 2003, 91, 167-172.

72. Y. Matsumura, Adv. Drug Delivery Rev., 2011, 63, 184-192.

73. G. L. Wang, B. H. Jiang, E. a Rue and G. L. Semenza, Proc. Natl. Acad. Sci. U. S. A., 1995, 92, 5510-5514.

74. G. Semenza, Nat. Rev. Cancer, 2003, 3, 721.

75. H. Zhong, A. M. De Marzo, E. Laughner, M. Lim, D. A. Hilton, D. Zagzag, P. Buechler, W. B. Isaacs, G. L. Semenza and J. W. Simons, Cancer Res., 1999, 59, 5830-5835.

76. B. Onnis, A. Rapisarda and G. Melillo, J. Cell. Mol. Med., 2009, 13, 27802786.

77. D. J. Brennan, K. Jirstrom, A. Kronblad, R. C. Millikan, G. Landberg, M. J. Duffy, L. Rydén, W. M. Gallagher and S. L. O’Brien, Clin. cancer Res., 2006, 12, 6421-6431.

78. S. K. Chia, C. C. Wykoff, P. H. Watson, C. Han, R. D. Leek, J. Pastorek, K. C. Gatter, P. Ratcliffe and A. L. Harris, J. Clin. Oncol., 2001, 19, 3660-3668.

79. D. Generali, S. B. Fox, A. Berruti, M. P. Brizzi, L. Campo, S. Bonardi, S. M. Wigfield, P. Bruzzi, A. Bersiga, G. Allevi, M. Milani, S. Aguggini, L. Dogliotti, A. Bottini and A. L. Harris, Endocr.-Relat. Cancer, 2006, 13, 921-930.

80. D. Generali, A. Berruti, M. P. Brizzi, L. Campo, S. Bonardi, S. Wigfield, A. Bersiga, G. Allevi, M. Milani, S. Aguggini, V. Gandolfi, L. Dogliotti, A. Bottini, A. L. Harris and S. B. Fox, Clin. Cancer Res., 2006, 12, 4562-4568.

81. S. A. Hussain, R. Ganesan, G. Reynolds, L. Gross, A. Stevens, J. Pastorek, P. G. Murray, B. Perunovic, M. S. Anwar, L. Billingham, N. D. James, D. Spooner, C. J. Poole, D. W. Rea and D. H. Palmer, Br. J. Cancer, 2007, 96, 104-109.

82. C. Trastour, E. Benizri, F. Ettore, A. Ramaioli, E. Chamorey, J. Pouysségur and E. Berra, Int. J. Cancer, 2007, 120, 1451-1458.

83. N. J. Mabjeesh, D. Escuin, T. M. LaVallee, V. S. Pribluda, G. M. Swartz, M. S. Johnson, M. T. Willard, H. Zhong, J. W. Simons and P. Giannakakou, Cancer Cell, 2003, 3, 363-375.

84. C. Sweeney, G. Liu, C. Yiannoutsos, J. Kolesar, D. Horvath, M. J. Staab, K. Fife, V. Armstrong, A. Treston, C. Sidor and G. Wilding, Clin. Cancer Res., 2005, 11, 6625-6633. 
85. M. Harrison, N. Hahn and R. Pili, Invest. New Drugs, 2011, 29, 1465-1474.

86. J. Y. Bruce and H. Avenue, Invest. New Drugs, 2012, 30, 794-802.

87. A. Rapisarda, R. Shoemaker and G. Melillo, Cell Cycle, 2004, 3, 172-175.

88. M. Xia, K. Bi, R. Huang, M.-H. Cho, S. Sakamuru, S. C. Miller, H. Li, Y. Sun, J. Printen, C. P. Austin and J. Inglese, Mol. Cancer, 2009, 8, 117.

89. D. Bertozzi, J. Marinello, S. G. Manzo, F. Fornari, L. Gramantieri and G. Capranico, Mol. Cancer Ther., 2013, 13, 239-248.

90. A. a Miller, A. Al Omari, D. J. Murry and D. Case, Lung Cancer, 2006, 54, 379-385.

91. L. M. Greenberger, I. D. Horak, D. Filpula, P. Sapra, M. Westergaard, H. F. Frydenlund, C. Albaek, H. Schrøder and H. Ørum, Mol. Cancer Ther., 2008, 7, 3598-3608.

92. X. Liu, M.-H. Xiong, X.-T. Shu, R.-Z. Tang and J. Wang, Mol. Pharm., 2012, 9, 2863-2874.

93. K. Brusselmans, F. Bono, P. Maxwell, Y. Dor, M. Dewerchin, D. Collen, J. M. Herbert and P. Carmeliet, J. Biol. Chem., 2001, 276, 39192-39196.

94. M. a Maynard, A. J. Evans, T. Hosomi, S. Hara, M. a S. Jewett and M. Ohh, FASEB J., 2005, 19, 1396-1406.

95. P. Maxwell, M. Wiesener and G. Chang, Nature, 1999, 399, 271-275.

96. B. Bao, A. S. Azmi, S. Ali, A. Ahmad, Y. Li, S. Banerjee, D. Kong and F. H. Sarkar, Biochim. Biophys. Acta, 2012, 1826, 272-296.

97. Y. Xia, H.-K. Choi and K. Lee, Eur. J. Med. Chem., 2012, 49, 24-40.

98. P. Ellinghaus, I. Heisler, K. Unterschemmann, M. Haerter, H. Beck, S. Greschat, A. Ehrmann, H. Summer, I. Flamme, F. Oehme, K. Thierauch, M. Michels, H. Hess-Stumpp and K. Ziegelbauer, Cancer Med., 2013, 611-624.

99. http://trialfinder.bayerscheringpharma.de/html/pdf/15044_Study_Synopsis_ CTP.pdf.

100. J. S. Carew, J. a Esquivel, C. M. Espitia, C. M. Schultes, M. Mülbaier, J. D. Lewis, B. Janssen, F. J. Giles and S. T. Nawrocki, PLoS One, 2012, 7, e31120.

101. Y. S. Chang, J. Adnane, P. a Trail, J. Levy, A. Henderson, D. Xue, E. Bortolon, M. Ichetovkin, C. Chen, A. McNabola, D. Wilkie, C. a Carter, I. C. a Taylor, M. Lynch and S. Wilhelm, Cancer Chemother. Pharmacol., 2007, 59, 561-574.

102. L. Liu, R. L. K. Ho, G. G. Chen and P. B. S. Lai, Clin. Cancer Res., 2012, 18, 5662-5671.

103. M. Wangpaichitr and N. Savaraj, Mol. Cancer, 2008, 7, 1506-1513.

104. N. J. Mabjeesh, D. E. Post, M. T. Willard, B. Kaur, E. G. Van Meir and J. W. Simons, Cancer Res., 2002, 62, 2478-2482.

105. M.-A. Dimopoulos, C. S. Mitsiades, K. C. Anderson and P. G. Richardson, Clin. Lymphoma, Myeloma Leuk. 2011, 11, 17-22.

106. S. Welsh, R. Williams, A. Birmingham, J. Newman, D. Kirkpatrick and G. Powis, Mol. Cancer Ther., 2003, 2, 235-243. 
107. E. Hur, K. Y. Chang, E. Lee, S. Lee and H. Park, Mol. Pharmacol., 2001, 59, 1216-1224.

108. L. C. J. Baker, J. K. R. Boult, S. Walker-Samuel, Y.-L. Chung, Y. Jamin, M. Ashcroft and S. P. Robinson, Br. J. Cancer, 2012, 106, 1638-1647.

109. N. Chau, P. Rogers, W. Aherne, I. F. That, D. Block, V. Carroll, I. Collins, E. Mcdonald, P. Workman and M. Ashcroft, Cancer Res., 2005, 65, 4918-4929.

110. E.-J. Yeo, Y.-S. Chun, Y.-S. Cho, J. Kim, J.-C. Lee, M.-S. Kim and J.-W. Park, J. Natl. Cancer Inst., 2003, 95, 516-525.

111. S. H. Li, D. H. Shin, Y.-S. Chun, M. K. Lee, M.-S. Kim and J.-W. Park, Mol. Cancer Ther., 2008, 7, 3729-3738.

112. J. Mun, A. A. Jabbar, N. S. Devi, S. Yin, Y. Wang, C. Tan, D. Culver, J. P. Snyder, E. G. Van Meir and M. M. Goodman, J. Med. Chem., 2012, 55, 6738-6750.

113. E. Miranda, I. K. Nordgren, A. L. Male, C. E. Lawrence, F. Hoakwie, F. Cuda, W. Court, K. R. Fox, P. a Townsend, G. K. Packham, S. a Eccles and A. Tavassoli, J. Am. Chem. Soc., 2013, 135, 10418-10425.

114. J. M. Heddleston, Z. Li, J. D. Lathia, S. Bao, a B. Hjelmeland and J. N. Rich, Br. J. Cancer, 2010, 102, 789-795.

115. S. J. Conley, E. Gheordunescu, P. Kakarala, B. Newman, H. Korkaya, A. N. Heath, S. G. Clouthier and M. S. Wicha, Proc. Natl. Acad. Sci., 2012, 109, 2784-2789.

116. R. K. Ambasta, A. Sharma and P. Kumar, Vasc. Cell, 2011, 3, 26.

117. D. Shweiki, A. Itin, D. Soffer and E. Keshet, Nature, 1992, 359, 843-845.

118. J. Forsythe, B. Jiang, N. Iyer, F. Agani, S. W. Leung, R. D. Koos and G. L. Semenza, Mol. Cell Biol., 1996, 16, 4604-4613.

119. B. Jiang, F. Agani, A. Passaniti and G. Semenza, Cancer Res., 1997, 57, 5328-5335.

120. A. Rapisarda and G. Melillo, Nat. Rev. Clin. Oncol., 2012, 9, 378-390.

121. A. Rapisarda, M. Hollingshead, B. Uranchimeg, C. a Bonomi, S. D. Borgel, J. P. Carter, B. Gehrs, M. Raffeld, R. J. Kinders, R. Parchment, M. R. Anver, R. H. Shoemaker and G. Melillo, Mol. Cancer Ther., 2009, 8, 1867-1877.

122. K. Hashimoto, S. Man, P. Xu, W. Cruz-Munoz, T. Tang, R. Kumar and R. S. Kerbel, Mol. Cancer Ther., 2010, 9, 996-1006.

123. W. M. Merritt, A. M. Nick, A. R. Carroll, C. Lu, K. Matsuo, N. Jennings, S. Zhang, Y. G. Lin, W. A. Spannuth, A. A. Kamat, R. L. Stone, M. M. K. Shahzad, R. L. Coleman and A. K. Sood, Mol. Cancer Ther., 2010, 9, 985-995.

124. K. Burkitt, S. Y. Chun, D. T. Dang and L. H. Dang, Mol. Cancer Ther., 2009, 8, 1148-1156.

125. S. Kummar, M. Raffeld, L. Juwara, Y. Horneffer, A. Strassberger, D. Allen, S. M. Steinberg, A. Rapisarda, S. D. Spencer, W. D. Figg, X. Chen, I. B. Turkbey, P. Choyke, A. J. Murgo, J. H. Doroshow and G. Melillo, Clin. Cancer Res., 2011, 17, 5123-5131. 
126. I. Zighelboim, J. D. Wright, F. Gao, A. S. Case, L. S. Massad, D. G. Mutch, M. a Powell, P. H. Thaker, E. L. Eisenhauer, D. E. Cohn, F. a Valea, A. Alvarez Secord, L. T. Lippmann, F. Dehdashti and J. S. Rader, Gynecol. Oncol., 2013, 130, 64-68.

127. P. Sapra, P. Kraft, F. Pastorino, D. Ribatti, M. Dumble, M. Mehlig, M. Wang, M. Ponzoni, L. M. Greenberger and I. D. Horak, Angiogenesis, 2011, 14, 245-253.

128. J. Overgaard, Radiother. Oncol., 2011, 100, 22-32.

129. M. L. Janssen, W. J. Oyen, I. Dijkgraaf, L. F. Massuger, C. Frielink, D. S. Edwards, M. Rajopadhye, H. Boonstra, F. H. Corstens and O. C. Boerman, Cancer Res., 2002, 62, 6146-6151.

130. M. Yoshimoto, K. Ogawa, K. Washiyama, N. Shikano, H. Mori, R. Amano and K. Kawai, Int. J. Cancer, 2008, 123, 709-715.

131. A. Mitra, A. Nan, J. C. Papadimitriou, H. Ghandehari and B. R. Line, Nucl. Med. Biol., 2006, 33, 43-52.

132. S. Sofou, Int. J. Nanomed., 2008, 3, 181-199.

133. J. Cheng, K. T. Khin, G. S. Jensen, A. Liu and M. E. Davis, Bioconjugate Chem., 2003, 14, 1007-1017.

134. S. Eliasof, D. Lazarus, C. G. Peters, R. I. Case, R. O. Cole, J. Hwang, T. Schluep, J. Chao, J. Lin, Y. Yen, H. Han, D. T. Wiley, J. E. Zuckerman and M. E. Davis, Proc. Natl. Acad. Sci., 2013, 110, 15127-15132.

135. C. Young, T. Schluep, J. Hwang and S. Eliasof, Curr. Bioact. Compd., 2011, 7, 8-14.

136. T. Numbenjapon, J. Wang, D. Colcher, T. Schluep, M. E. Davis, J. Duringer, L. Kretzner, Y. Yen, S. J. Forman and A. Raubitschek, Clin. Cancer Res., 2009, 15, 4365-4373.

137. T. Schluep, J. Hwang, J. Cheng, J. D. Heidel, D. W. Bartlett, B. Hollister and M. E. Davis, Clin. Cancer Res., 2006, 12, 1606-1614.

138. T. Schluep, J. Cheng, K. T. Khin and M. E. Davis, Cancer Chemother. Pharmacol., 2006, 57, 654-662.

139. S. R. Kabir, D. Lazarus and S. Eliasof, Mol. Cancer Ther., 2011, 10, C38.

140. T. Schluep, J. Hwang, I. J. Hildebrandt, J. Czernin, C. Hang, J. Choi, C. A. Alabi, B. C. Mack and M. E. Davis, Proc. Natl. Acad. Sci. U. S. A., 2009, 106, 11394-11399.

141. T. S. Ng, D. Wert, H. Sohi, D. Procissi, D. M. Colcher, A. a Raubitschek and R. E. Jacobs, Clin. Cancer Res., 2013, 19, 2518-2527.

142. Y. Yen, L. a. Coerver, E. G. Garmey, D. L. Kalinoski, M. Koczywas, J. a. Neidhart, J. D. Neidhart, J. J. Peterkin, R. K. Ramanathan, J. Ryan and G. J. Weiss, Mol. Cancer Ther., 2011, 10, A97.

143. Y. Yen, T. Synold, G. J. Weiss, T. Schluep and J. Ryan, Eur. J. Cancer Suppl., 2010, 8, 134-135.

144. (http://ceruleanrx.com/wp-content/uploads/2013/03/Top-line-Phase-2bNSCLC-Results-032213-FINAL.pdf). 
145. T. A. Hensing, T. Karrison, E. G. Garmey, M. G. Hennessy and R. Salgia, J. Clin. Oncol., 2013, 31, suppl; abstr TPS7610.

146. D. Lazarus, C. Peters and K. Deotale, Cancer Res., 2013, 73, 12-14.

147. S. M. Keefe, R. Cohen, S. Eliasof, E. G. Garmey, M. Hennessy, K. M. Mykulowicz, D. Pryma and N. Haas, Am. Assoc. Cancer Res., 2013, 2419, 1625936.

148. Cancer Discov., 2013, 3, OF3, DOI: 10.1158/2159-8290.CD-NB2013-155.

149. http://ir.ceruleanrx.com/releasedetail.cfm?releaseid=914714.

150. G. L. Semenza, Drug Discovery Today, 2007, 12, 853-859.

151. E. A. Perez, A. Awada, J. O’Shaughnessy, H. S. Rugo, C. Twelves, S.-A. Im, P. Gomez-Pardo, L. S. Schwartzberg, V. Dieras, D. A. Yardley, D. A. Potter, A. Malliez, A. Moreno-Aspitia, J. S. Ahn, C. Zhao, U. Hoch, M. Tagliaferri, A. L. Hannah and J. Cortes, Lancet Oncol., 2015, 16, 1556-1568. 